OPEN ACCESS

Edited by:

Sally C. Kent,

University of Massachusetts Medical

School, United States

Reviewed by:

Yang Dai,

Biomedical Research Institute of

Southern California, United States

Adriana Karina Chavez-Rueda,

Mexican Social Security Institute (IMSS), Mexico

Steven Paraskevas,

McGill University, Canada

*Correspondence:

Guido Sebastian

sebastianiguido@gmail.com

${ }^{t}$ These authors share first authorship

Specialty section: This article was submitted to Autoimmune and

Autoinflammatory Disorders,

a section of the journal

Frontiers in Immunology

Received: 19 March 2021 Accepted: 10 May 2021

Published: 09 June 2021

Citation:

Grieco GE, Fignani D, Formichi C, Nigi L, Licata G, Maccora C, Brusco N,

Sebastiani $G$ and Dotta F (2021)

Extracellular Vesicles in Immune

System Regulation and Type 1 Diabetes: Cell-to-Cell Communication Mediators, Disease Biomarkers, and Promising Therapeutic Tools.

Front. Immunol. 12:682948. doi: 10.3389/fimmu.2021.682948

\section{Extracellular Vesicles in Immune System Regulation and Type 1 Diabetes: Cell-to-Cell Communication Mediators, Disease Biomarkers, and Promising Therapeutic Tools}

\author{
Giuseppina Emanuela Grieco ${ }^{1,2 \dagger}$, Daniela Fignani ${ }^{1,2 \dagger}$, Caterina Formichi ${ }^{1,2,3}$, Laura Nigi ${ }^{1,2,3}$, \\ Giada Licata $^{1,2}$, Carla Maccora ${ }^{1,2,3}$, Noemi Brusco ${ }^{1,2}$, Guido Sebastiani ${ }^{1,2 *}$ \\ and Francesco Dotta ${ }^{1,2,3,4}$
}

\begin{abstract}
${ }^{1}$ Diabetes Unit, Department of Medicine, Surgery and Neurosciences, University of Siena, Siena, Italy, ${ }^{2}$ Fondazione Umberto Di Mario, c/o Toscana Life Sciences, Siena, Italy, ${ }^{3}$ UOC Diabetologia, Azienda Ospedaliera Universitaria Senese, Siena, Italy,

4 Tuscany Centre for Precision Medicine (CReMeP), Siena, Italy
\end{abstract}

Extracellular vesicles (EVs) are generated by cells of origin through complex molecular mechanisms and released into extracellular environment. Hence, the presence of EVs has been described in multiple biological fluids and in most cases their molecular cargo, which includes non-coding RNAs (ncRNA), messenger RNAs (mRNA), and proteins, has been reported to modulate distinct biological processes. EVs release and their molecular cargo have been demonstrated to be altered in multiple diseases, including autoimmune diseases. Notably, numerous evidence showed a relevant crosstalk between immune system and interacting cells through specific EVs release. The crosstalk between insulinproducing pancreatic $\beta$ cells and immune system through EVs bidirectional trafficking has yet started to be deciphered, thus uncovering an intricate communication network underlying type 1 diabetes (T1D) pathogenesis. EVs can also be found in blood plasma or serum. Indeed, the assessment of circulating EVs cargo has been shown as a promising advance in the detection of reliable biomarkers of disease progression. Of note, multiple studies showed several specific cargo alterations of EVs collected from plasma/serum of subjects affected by autoimmune diseases, including T1D subjects. In this review, we discuss the recent literature reporting evidence of EVs role in autoimmune diseases, specifically focusing on the bidirectional crosstalk between pancreatic $\beta$ cells and immune system in T1D and highlight the relevant promising role of circulating EVs as disease biomarkers.

Keywords: extracellular vesicles, exosomes, type 1 diabetes, autoimmunity, immune regulation, pancreatic islets 


\section{INTRODUCTION}

Type 1 diabetes (T1D) is an autoimmune disease characterized by chronic hyperglycaemia, caused by $\beta$ cells destruction due to specific autoreactive $\mathrm{T}$ cells and other immune cells. Despite this simplified definition, the striking heterogeneity of T1D pathogenetic mechanisms has been investigated and reported in multiple studies $(1,2)$. Such heterogeneity is clinically characterized by different age at onset, disease progression timing and severity (3). The elucidation of additional pathogenetic mechanisms may help to further understand the pathological bases of T1D heterogeneity both at molecular and clinical level.

Extracellular vesicles (EVs) have been recently reported to be involved in multiple diseases and shown to represent pivotal mediators of several pathogenetic mechanisms. Different types of EVs can be identified in biofluids based on their size, content, and surface markers. They are mainly classified in exosomes and ectosomes, both potentially involved in cell-to-cell communication. As a matter of fact, recent evidence demonstrated that under certain conditions, immune cells can communicate with each other and with other cell types through specific mechanisms driven by EVs release and uptake. Specifically, pioneering studies showed that during T1D progression, pancreatic islet infiltrating lymphocytes secrete a distinct subset of EVs capable of transferring a specific cluster of microRNAs (miRNAs) to $\beta$ cells, thus causing apoptotic pathways activation. On the other hand, $\beta$ cell EVs release may influence immune cells function through direct lymphocytes activation, or distinct EVs containing autoantigens release and subsequent uptake by local antigen-presenting cells (APCs). Taken together, such studies indicate that an active communication channel between $\beta$ cell and immune system, based on EVs secretion, may be involved in the pathogenesis and progression of T1D. Of note, it has been also demonstrated that EVs released by pancreatic $\beta$ cells can contain autoantigens which are transported to neighboring immune cells, thus potentially contributing to the typical autoimmune response (4-6).

Considering EVs ability to mediate signals exchange among different cell types of multiple tissues/organs, it is conceivable that EVs cargo could be an interesting tool to evaluate pathogenetic mechanisms involved in T1D and other autoimmune diseases as well as for the identification of potential biomarkers for the prediction and the progression of the disease. The communication features of EVs could also be used to develop novel therapeutic tools thus opening the way to innovative avenues for the cure or prevention of T1D. As a matter of fact, several evidence of EVs therapeutic ability to induce immunomodulatory effects or immunotolerance have been reported in different diseases.

\section{EXTRACELLULAR VESICLES (EVs) BIOGENESIS, CLASSIFICATION, AND COMPOSITION}

Extracellular vesicles (EVs) are a highly heterogeneous population of phospholipid bilayer membrane-enclosed vesicles, currently classified based on their biogenesis, release mechanism, size, content, and function (7-10). Although the classification of EVs is continuously evolving, they are usually classified into two major categories: ectosomes and exosomes $(11,12)$.

Ectosomes are directly shed from the plasma membrane and include microvesicles and large vesicles ranging from $\sim 50 \mathrm{~nm}$ to $1 \mu \mathrm{m}$ in diameter. On the contrary, exosomes have endosomal origin and are characterized by a $\sim 40$ to $160 \mathrm{~nm}$ diameter $(\sim 100$ $\mathrm{nm}$ on average) $(13,14)$. Their biogenesis and secretion include specific intracellular processes determining selective molecules cargo loading that potentially defines their composition and, consequently, their function (15-17). Exosomes are generated through a process of double invagination of the plasma membrane. The first step leading to the invagination process results into de novo formation of an early-sorting endosome (ESE) characterized by cell-surface proteins and soluble proteins $(18,19)$. Moreover, since ESE continuously exchanges cargo constituents with endoplasmic reticulum (ER), trans-Golgi network (TGN), and mitochondria, it is specifically enriched for proteins and molecules typical of these organelles. Subsequently, the early-sorting endosome can mature into a late-sorting endosome through a second invagination of the plasma membrane leading to the generation of the Multi Vesicular Bodies (MVBs) composed by multiple intraluminal vesicles (ILVs). Based on the invagination volume, ILVs show different sizes and content $(20,21)$.

MVBs play an essential role both as intermediate progenitor extracellular vesicles and as part of the degradative lysosomal pathway. In details, MVBs can: (i) fuse with lysosomes resulting in the digestion of their ILVs or (ii) fuse with the plasma membrane thus leading to the release of ILVs as exosomes (Figure 1) $(22,23)$.

The endosomal sorting complex required for transport (ESCRT) plays an essential role in the generation of MVBs. ESCRT mechanism consists of 4 protein subcomplexes (ESCRTI to IV) acting in a progressive fashion to mediate exosome generation (37-43). The presence of relevant ESCRT proteins in purified exosomes [e.g., tumor susceptibility gene 101 protein (TSG101) and apoptosis-linked gene 2-interacting protein X (ALIX)], represents the evidence of their MVBs origin (18, 44-46). Several studies suggested that ESCRT-independent mechanisms are also involved in MVBs and ILVs biogenesis. These mechanisms involve lipids, tetraspanins and/or heat shock proteins (HSPs) (47-51), thus opening to the presence of multiple parallel mechanisms of exosomes biogenesis.

As a result of their endosomal origin, exosomes carry proteins associated with MVBs formation (Alix and TSG101, as previously cited) and/or in membrane transport and fusion (Rab proteins and annexins) as well as proteins mostly associated with lipid microdomains and exposed to the external exosomes surface, such as integrins and tetraspanins (e.g., CD63, CD9, and CD81) (24-28) (Figure 1). However, the identification of novel exosomal molecules is rapidly evolving. Indeed, recent studies demonstrated that Annexin A1 is a specific marker of microvesicles shed from the plasma 


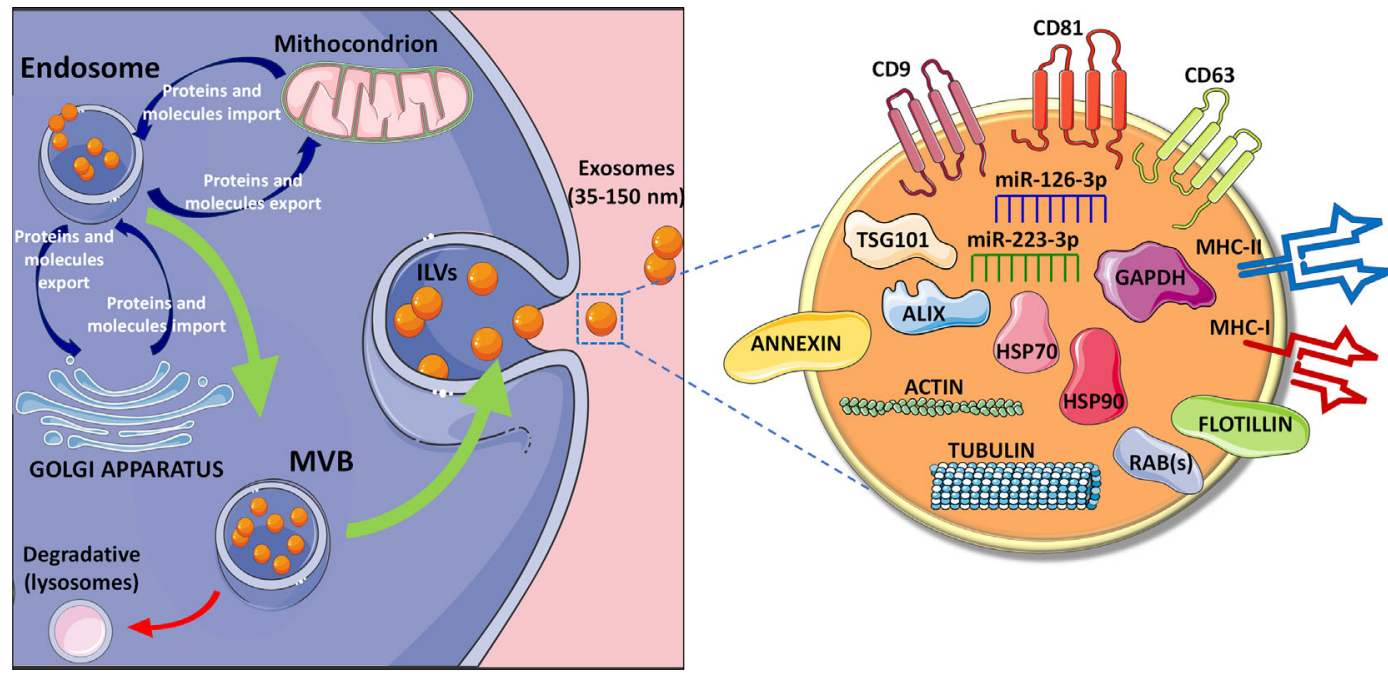

FIGURE 1 | Exosomes biogenesis and composition. Exosomes biogenesis is based on a process of double invagination of the plasma membrane. The first step leading to the invagination process results into de novo formation of an early-sorting endosome characterized by cell-surface proteins and soluble proteins. Following the continuous exchange (import and export) of specific proteins and molecules from endosomes and mitochondria as well as with Trans Golgi network, the earlysorting endosome can mature into a late-sorting endosome through a second invagination of the plasma membrane leading to the generation of the Multi Vesicular Bodies (MVBs) composed by multiple intraluminal vesicles (ILVs). Then, MVBs can: (i) fuse with lysosomes resulting in the digestion of their ILVs or (ii) fuse with the plasma membrane thus leading to the release of ILVs as exosomes (22, 23). Exosomes expose several membrane proteins, such as tetraspanins (CD9, CD81, CD63) (24-28) and MHC molecules, both class I and class II, as well as Annexin and Flotillin. Moreover, exosomes content is highly variable depending on the cell of origin, but usually they contain cytoskeleton proteins (e.g., actin and tubulin), heat shock proteins such as HSP70 and HSP90, proteins associated to metabolism (GAPDH) (29-31), as well as specific proteins (e.g., ALIX, TSG101 and RAB proteins). Exosomes also contains different RNA species such as microRNAs, among which the most reported are miR-126-3p and miR-223-3p (32-36).

membrane, while the tetraspanin CD63 is a typical marker of those vesicles released through ESCRT-independent mechanisms, thus rendering these markers not specific for a pure exosome population (52-55). Other proteins identified in almost all exosomes, independently of their origin, are Heat Shock Proteins (HSPs) (e.g., HSP90), cytoskeleton proteins (actin and tubulins), metabolic proteins (GADPH), and major histocompatibility complex (MHC) class I and II molecules (29-31).

Importantly, exosomes also contain different species of RNAs that can be transferred to recipient cells (56-62). Among these, microRNAs (miRNAs), small non-coding RNAs approximately 19 to $24 \mathrm{nts}$ in length, have generated a particular interest in the scientific community for their regulatory function. Two putative pathways of miRNAs sorting into exosomes have been suggested: (i) neural sphingomyelinase 2 (nSMase2)-dependent pathway; (ii) sumoylated heterogeneous nuclear ribonucleoprotein (hnRNP)based sorting. Although additional studies are needed, it was demonstrated that overexpression of nSMase 2 causes an increase in the amount of exosomal miRNAs, while its inhibition leads to a reduced number $(63,64)$. Regarding hnRNP-based sorting, it has been reported that sumoylated hnRNPA2B1 recognizes the GGAG motif in the $3^{\prime}$ portion of miRNAs sequences triggering a specific sorting into EVs (65). Such evidence underlines that the 3 '-end of the miRNA sequence contains an important sorting signal motives, which strongly contributes to the miRNAs sorting into EVs (66). However, the presence of specific miRNAs sequence motives is not the only leading cue determining its loading into EVs; indeed, loading mechanisms can also be modulated by miRNA-induced silencing complex (miRISC). Of note, the specific knockout of ribonucleoprotein complex Ago2 (main component of RISC complex) induced the reduction of some EVs enriched miRNAs (miR-142-3p, miR-150, and miR-451) from HEK293T cells (67), thus indicating that the presence of a fully functional miRISC protein complex is fundamental for miRNAs sorting through EVs.

Different miRNAs, such as miR-126-3p and miR-223-3p, have been reported to be enriched and secreted through EVs (Figure 1), even though additional confirmatory studies are needed to definitely characterize specific EVs miRNAs content (32-36).

Interestingly, in order to regularly update information about EVs miRNAs, several databases across different biofluids and isolation methods have been generated, such as the extracellular vesicles miRNA database (http://bioinfo.life.hust.edu.cn/EVmiRNA), Vesiclepedia (http://microvesicles.org/), ExoCarta (http://exocarta. org/), and miRDB (http://mirdb.org/) $(26,27,68,69)$.

\section{EVs ROLE IN IMMUNE SYSTEM HOMEOSTASIS AND IMMUNE CELLS CROSSTALK}

In order to support cellular homeostasis and provide host defense, immune system has developed direct and indirect 
communication mechanisms, such as the release of soluble factors or the transfer of information through EVs (70). The latter has been extensively investigated in macrophages, dendritic cells (DCs), B cells and T cells. Indeed, EVs secreted by all these cells are highly interconnected and act in several molecular mechanisms controlling immune system function, mainly through the modulation of initiation, expansion, and maintenance of innate and adaptive immune responses (9, 71, 72).

Several studies have shown that macrophages infected with different intracellular pathogens, such as Mycobacterium tuberculosis, Bacillus-Calmette-Guèrin (BCG), Salmonella, Toxoplasma, or Leishmania, can release EVs carrying pathogens-associated molecular patterns (PAMPs). The exposure of naïve macrophages to such EVs leads to an increased production of cytokines via Toll-like receptors (TLR) activation, then promoting the exacerbation of the immune response $(73,74)$. As a matter of fact, in other two studies, it was demonstrated that EVs released by monocytes exposed to interferon alpha (IFN- $\alpha$ ), lipopolysaccharide (LPS), or a combination of both, were able to enhance the production of proinflammatory cytokines by not-treated monocytes as well as by epithelial cells, mainly through the activation of TLR4/nuclear factor kappa-light-chain-enhancer of activated B (NF-kB) cells pathway $(75,76)$.

Bacteria and parasites can also release specific EVs [e.g., outer-membrane vesicles (OMV)] carrying specific molecules having immunomodulatory properties, such as LPS and lipoproteins $(77,78)$. Furthermore, bacterial-derived EVs contribute to the exacerbation of bacterial infections by carrying and releasing elements inducing resistance to antimicrobials and complement system factors, as well as by transferring virulent factors. In fact, these EVs seem to be a vehicle for the diffusion of PAMPs which consequently lead to different events: (i) triggering of pattern recognition receptors (PRRs) signalling and inflammasome activation; (ii) triggering of stimulator of interferon genes (STING) pathways and (iii) activation of host innate immune cells, finally leading to the amplification of tissue damage and inflammation (79-82).

Furthermore, macrophage- and monocyte-derived EVs are also involved in inflammatory processes. Indeed, it was reported upon LPS stimulation, they can transfer chemokines, such as tumor necrosis factor $\alpha$ (TNF- $\alpha$ ), C-C motif chemokine ligand 3 (CCL3), C-C Motif Chemokine Ligand 5 (CCL5), granulocyte colony-stimulating factor (G-CSF), interleukin-1 receptor $\alpha$ (IL$1 \mathrm{R} \alpha$ ), and $\mathrm{C}-\mathrm{X}-\mathrm{C}$ motif chemokine ligand 2 (CXCL2) that induce the synthesis of additional pro- or anti-inflammatory mediators and act as homing signals for other immune cells (83). These data suggest that EVs secreted by activated macrophages strongly work as signal for immune response by host cells (83).

Interestingly, in inflammatory processes, macrophagesderived EVs are also able to induce the activation of memory $\mathrm{CD}^{+}$and $\mathrm{CD}^{+} \mathrm{T}$ cells. In fact, intranasal administration of exosomes isolated from BCG-infected macrophages of M. bovis induces the proliferation of memory $\mathrm{CD} 4^{+}$and $\mathrm{CD} 8^{+}$ T cells (84).
In addition to monocytes/macrophages, also dendritic cells (DCs) have been reported to secrete EVs with essential roles for immune regulation processes. DCs, which are the main antigenpresenting cells (APC), canonically activate T lymphocytes through MHC-peptide complex (85). However, APCs can also indirectly activate lymphocyte, through the release of specific EVs $(86,87)$ carrying the entire MHC-peptide complex (88). However, it was also demonstrated that $\mathrm{T}$ cell stimulation by DCs-EVs is less effective than that by APCs $(89,90)$. It was hypothesized that this weaker stimulatory ability could be ascribed to a low capacity of EVs to $\mathrm{T}$ cell receptor (TCR) cross-linking, possibly due to their small size or to a different membrane composition $(91,92)$.

Given their function in several immune processes, the potential role of DCs-EVs in autoimmunity was taken into consideration for the presentation of intracellular antigens to immune cells. Importantly, several studies have shown that antigens presented by APCs can undergo intracellular transfer, where they are internalized by EVs and delivered to autoreactive T cells (93-95).

As lymphocytes can be targeted and activated by EVs released by other immune cells, they also release specific EVs involved in the crosstalk mechanisms regulating immune response in different contexts. The first evidence of lymphocyte-released EVs was reported in 1996 by Raposo et al., who demonstrated that human B cell-derived EVs are efficiently able to present MHC class II (MHC-II) peptide complexes (pMHC-II) to CD4 T cells in vitro (88). Later, it was demonstrated that the release of EVs by primary B cells, requires pMHC-II ligation with cognate TCR on $\mathrm{CD}^{+}{ }^{+} \mathrm{T}$ cells (96), CD40/IL-4 signalling, and relies on pathways mediated by NF-kB for $\mathrm{T}$ cell-induced $\mathrm{B}$ cell proliferation (97). Moreover, Rialland and colleagues showed that IgG-mediated B Cell Receptor (BCR) cross-linking in DOHH2 immortalized B cell line, stimulates EVs release, although to a minor extent with respect to TCR-pMHC-II interaction (98), which is the major determinant for EVs release by $\mathrm{B}$ cells. As an example, one of the potential targets of B cell-derived EVs are follicular DCs (FDCs) which are activated upon B cell-EVs exposure. As a matter of fact, B cell EVs are specifically uptaken by FDCs which, in turn, present MHC-II peptides to $\mathrm{CD}^{+} \mathrm{T}$ cells, leading to $\mathrm{T}$ cell differentiation, expansion or silencing depending on the pathological context (99).

An essential role in immune regulation is also played by $\mathrm{T}$ cells-derived EVs containing TCR/CD3 complexes (100) and mainly associated to antiviral immune response. It was recently observed that upon activation by DCs, T cells can release EVs containing genomic and mitochondrial DNA, which are then transferred to DCs, leading to the enhancement of antiviral responses via the cGAS (cyclic GMP-AMP Synthase)/STING cytosolic DNA-sensing pathway and subsequently inducing interferon regulatory factor 3 (IRF3)-dependent interferonregulated genes expression (101). These results suggest a potential feedback mechanism by which $\mathrm{T}$ cells enhance the activity of APCs, priming them to a more efficient response to the infections (71). We can speculate that this immunomodulatory 
mechanism could also occur toward Enteroviruses infection, which is one of the most investigated and described environmental risk factor in the pathogenesis of T1D.

Recent studies demonstrated that EVs subpopulations play different roles in immune cells, thus generating multiple immune responses. For instance, Whalund et al. observed that when DCs are loaded with the whole ovoalbumin (OVA) antigen, exosomes from OVA-pulsed DCs are more efficient in inducing antigenspecific $\mathrm{CD}^{+}{ }^{+} \mathrm{T}$-cells activation, and in eliciting antigen-specific IgG production respect to other microvesicles types. In this case, this was probably due to the greater ability of exosomes to carry high levels of the antigen, while in other microvesicles it was barely detectable (102).

Furthermore, similarly to healthy cells, also apoptotic cells have been reported to release extracellular vesicles (termed apoptotic extracellular vesicles, Apo-EVs) (103). The release of these EVs seems to occur during apoptosis and differs from apoptotic bodies formation. Apo-EVs have similar characteristics to those EVs released by healthy cells, in terms of cargo delivery and immune regulation; indeed, this peculiar EVs population mainly acts on inflammation, cancer and autoimmunity (103-105). Of note, Apo-EVs formation has also been proposed as a mechanism to facilitate the transport of autoantigens to APC, thus putatively playing a key role in the initiation of autoimmune reaction in situ. As an example, Dieudè and colleagues recently discovered a novel class of vesicles, namely apoptotic exosome-like vesicles, much more active than most known apoptotic bodies and released by endothelial cells following serum-free starvation induced-apoptosis. As a matter of fact, the injection of these class of vesicles into $\mathrm{C} 57 \mathrm{Bl} / 6$ mice was able to trigger the production of anti-LG3 autoantibodies (subunit of perlecan), thus enhancing the severity of graft rejection. Importantly, apoptotic exosome-like vesicles are particularly enriched of 20 s proteasome subunit, and since LG3 behaves as a proteasome substrate, authors further demonstrated that proteasome activity within apoptotic exosome-like vesicles directly regulates anti-LG3 autoantibody formation and allograft inflammation (106).

Overall, these data suggest that immune cells-derived EVs can exert similar functions as their parental cells, including immune stimulation or inhibition. Indeed, the crosstalk between immune cell populations through EVs physiologically contribute to the maintenance of immune system homeostasis, whose alterations can lead to several disorders, including autoimmune diseases.

\section{EVs AND AUTOIMMUNE DISEASES}

Accumulating evidence reveal that EVs from both immune and non-immune cells could play a key role into the regulation of immunity (107). As reported above, EVs are involved in the establishment, maintenance and modulation of autoimmune processes through different mechanisms (108).

EVs can be secreted by APC and may represent a source of autoantigens leading to the activation of autoreactive $\mathrm{T}$ lymphocytes (109-111). In fact, several in vitro studies showed the ability of APC EVs to directly or indirectly stimulate T cells in order to establish a "dialogue" required for their activation (89, 108, 112). Alternatively, EVs can interact with APC through multiple independent molecular mechanisms involving TCR complexes-MHC interaction (92), co-stimulatory molecules binding (108), or by direct EVs cargo internalization and processing $(7,92)$. Due to this variety of mechanisms, EVs can contribute to the pathogenetic molecular mechanisms of different immune-mediated diseases including multiple sclerosis (MS), rheumatoid arthritis (RA) and systemic lupus erythematosus (SLE).

Since EVs are enriched in the cerebrospinal fluid (CSF), they could also play a relevant role in nervous system autoimmune diseases such multiple sclerosis (MS) (93). MS, which represents the most common autoimmune demyelinating disease of the CNS (113), characterized by lesions of the blood-brain barrier (BBB) thus contributing to the trans-endothelial migration of autoreactive $\mathrm{T}$ cells into the CNS, inducing chronic neuroinflammation and demyelination $(93,114,115)$. In this context, endothelial cells and platelet-released EVs resulted increased in the peripheral blood of MS patients during relapses phases of the disease, consequently causing enhanced endothelial permeability and increased migration of immune cells $(116,117)$. In addition, it has been demonstrated that EVs released by infiltrating $\mathrm{T}$ cells, containing $\mathrm{C}-\mathrm{C}$ chemokine ligand 5 (CCL5) and arachidonic acid, are able to enhance immune cells recruitment thus contributing to further BBB disruption (117). Finally, microglia-derived EVs, containing MHC class II molecules, also contribute to restimulate infiltrated lymphocytes thus leading to the spreading of neuronal antigens outside the CNS $(115,118)$.

Another autoimmune disorder in which EVs have been reported to play a pivotal role is rheumatoid arthritis (RA), a chronic inflammatory autoimmune disease characterized by joint inflammation and destruction associated with systemic symptoms (113). Of interest, synovial fluid-derived EVs carry fibrinogen components and vimentin, thus stimulating autoantibodies production and contributing to the generation of immune complexes $(110,119)$. Therefore, pathogenetic molecular mechanisms of RA are strongly related to EVsmediated cell-to-cell communication among immune cells, synoviocytes, endothelial cells, and chondrocytes, through different mechanisms $(93,110,113,119)$. On the other side, EVs derived from synoviocytes released in inflammatory conditions may stimulate adjacent cells to secrete mediators of inflammation, leading to cartilage damage. Furthermore, EVs also contribute to RA pathogenesis by promoting the survival of autoreactive $\mathrm{T}$ lymphocytes. In fact, inflamed tissue-resident fibroblasts secrete TNF- $\alpha^{+}$exosomes which are uptaken by autoreactive $\mathrm{T}$ lymphocytes, thus becoming resistant to the activation induced cell death (AICD) (120). Moreover, the enzymatic cargo of EVs can also contribute to RA pathogenesis, leading to the degradation of the cartilage matrix caused by the secretion of proteinase and glycosidase enzymes by synovial fibroblasts $(115,121,122)$. On the other side, in the RA synovial fluid an increase of leukocyte derived EVs has also been 
described (123). In particular, EVs derived from T lymphocytes and macrophages are able to induce the secretion of metalloproteinases, proinflammatory mediators, and proangiogenic chemokines by synovial fibroblasts (121). Finally, it can be also hypothesized a role for platelet-derived EVs in RA angiogenesis occurring in synovia, promoting development and growth of synovial membrane and subsequent cartilage and bone destruction as well as articular remodeling $(108,110)$. Indeed, synovial fluid of RA patients has been reported to contain proinflammatory immune complexes generated by the association of platelet-derived microvesicles and citrullinated peptides autoantibodies (124). Furthermore, Boilard et al. (125) also demonstrated that platelets-released microvesicles play an active role in RA inflammatory processes being detected exclusively in joints of RA patients but not in those from control individuals. Of note, depletion of platelets in $\mathrm{K} / \mathrm{BxN}$ mice (rheumatoid arthritis animal model), was able to reduce arthritis severity, mainly through the reduction of IL-1 (125).

The same research group also demonstrated that activated platelets are able to release respiratory-competent mitochondria encapsulated in microparticles or as free organelles. Since mitochondria are a substrate for secreted phospholipase A2 IIA (sPLA2-IIA), the hydrolysis of the mitochondrial membrane by sPLA2-IIA yields inflammatory mediators (i.e., lysophospholipids, fatty acids, and mtDNA) that promote leukocyte activation and RA typical inflammation (126).

A specific role of EVs has also been reported in systemic lupus erythematosus (SLE). SLE is a chronic systemic autoimmune disease characterized by the presence of autoantibodies (antidouble stranded DNA and antinuclear antibodies), resulting in the deposition of immune complexes in several tissues, thus consequently leading to organs damage $(93,119)$. Of note, the role of EVs in SLE has recently been investigated (108). In fact, it has been shown that EVs released from apoptotic cells carry antigenic nuclear determinants, thus being targeted by anti-DNA and anti-nucleosome antibodies from SLE affected mice and from plasma of patients with SLE (127). Moreover, in SLE patients, circulating proinflammatory EVs, are able to induce TNF- $\alpha$ and IFN- $\alpha$ secretion by peripheral blood mononuclear cells (PBMC) through a TLR-mediated mechanism $(115,128,129)$. In addition, SLE-specific EVs cargo, composed of metalloproteinases, tissue factor and CD40, are able to induce VEGF production and chemokines secretion thus exacerbating pathological angiogenesis typical of SLE $(130,131)$. As an example, it has been reported that in advanced SLE vascular lesions, atherosclerotic plaques can release CD40 ligand ${ }^{+}$(CD40L)-microvesicles which can further stimulate endothelial cell proliferation and angiogenesis, thus contributing to the transition from stable to unstable plaques and to the worsening of SLE vascular lesions (130).

\section{EVs AND TYPE 1 DIABETES}

As already mentioned, EVs are essential components of cell-tocell communication, thus being involved in the crosstalk between different cell types. Among these, $\beta$ cells have been reported to actively communicate via EVs with other cells, including immune cells. Of note, several recently published studies specifically revealed a bidirectional crosstalk between $\beta$ cells and immune cells via EVs, both in physiological and pathological conditions (Table 1).

\section{EVs From Pancreatic $\beta$ Cells to Immune Cells}

The first evidence of EVs secretion by pancreatic $\beta$ cells was reported in 2011 (132). In this study, Sheng H. and colleagues showed that the murine $\beta$ cell line mouse insulinoma-6 (MIN6) was able to secrete EVs characterized by the typical pattern of exosomal markers, alongside with pancreatic islet $\beta$ cell autoantigens including GAD65. Of note, the exposure of splenocytes obtained from Non Obese Diabetic mice (NOD 68 weeks) to EVs isolated from MIN6 cells, induced the secretion of multiple inflammatory molecules including IL-6, IFN- $\gamma$, TNF$\alpha$, MCP-1, and IL-10. Of interest, cytokines release was completely abolished when splenocytes were isolated from TLR-innate signalling pathway MyD88-KO NOD mice; similarly, lymphocytes proliferation assay showed a significant reduction of the proliferation rate when MyD88-KO NOD mice splenocytes were exposed to MIN6 EVs respect to wild type splenocytes, thus suggesting that the inflammatory stimuli enclosed within MIN6 EVs may activate TLR signals via MyD88-dependent pathways, then favoring lymphocytes proliferation. Splenocytes exposure to MIN6 EVs also generated an increase of MHC class II, CD80 and CD86 costimulatory molecules on APC cells, paralleled by an increase of IFN- $\gamma$-secreting $\mathrm{T}$ cells. Importantly, authors also demonstrated that the intravenous injection of MIN6 EVs in Non Obese Resistant (NOR) mice induced a significant increase in insulitis. Indeed, the severity of insulitis or lymphocyte infiltration was three-fold higher in the NOR mouse group treated with MIN6 EVs for 7 days in comparison to untreated group, demonstrating a tight crosstalk between MIN6 and immune cells activation in autoimmune diabetes through EVs.

Among EVs cargo molecules released by pancreatic islet $\beta$ cells, insulin is of particular interest. In 2015, Vomund and colleagues demonstrated that NOD mouse $\beta$ cells can transfer vesicles containing insulin or its catabolites to tissue-resident APCs. Importantly, this result was confirmed also in human pancreatic islets. In this case, the EVs transfer, which required a close contact interaction between $\beta$ cells and APCs, was increased upon glucose stimulation and requires mobilization of intracellular $\mathrm{Ca}^{2+}$. Additionally, the authors observed that $\mathrm{CD}^{+} \mathrm{T}$ cells of diabetic NOD mice exposed to various peptides of the insulin B chain, are able to recognize the APCs vesicles-transferred antigens, thus reporting a potential mechanism through which $\beta$ cells become recognizable by autoreactive $\mathrm{T}$ cells in T1D upon autoantigens transfer through EVs (Figure 2) (4).

Recent studies further demonstrated the presence of islet autoantigens in $\beta$ cell-derived EVs and their specific release upon proinflammatory conditions. Cianciaruso and colleagues 


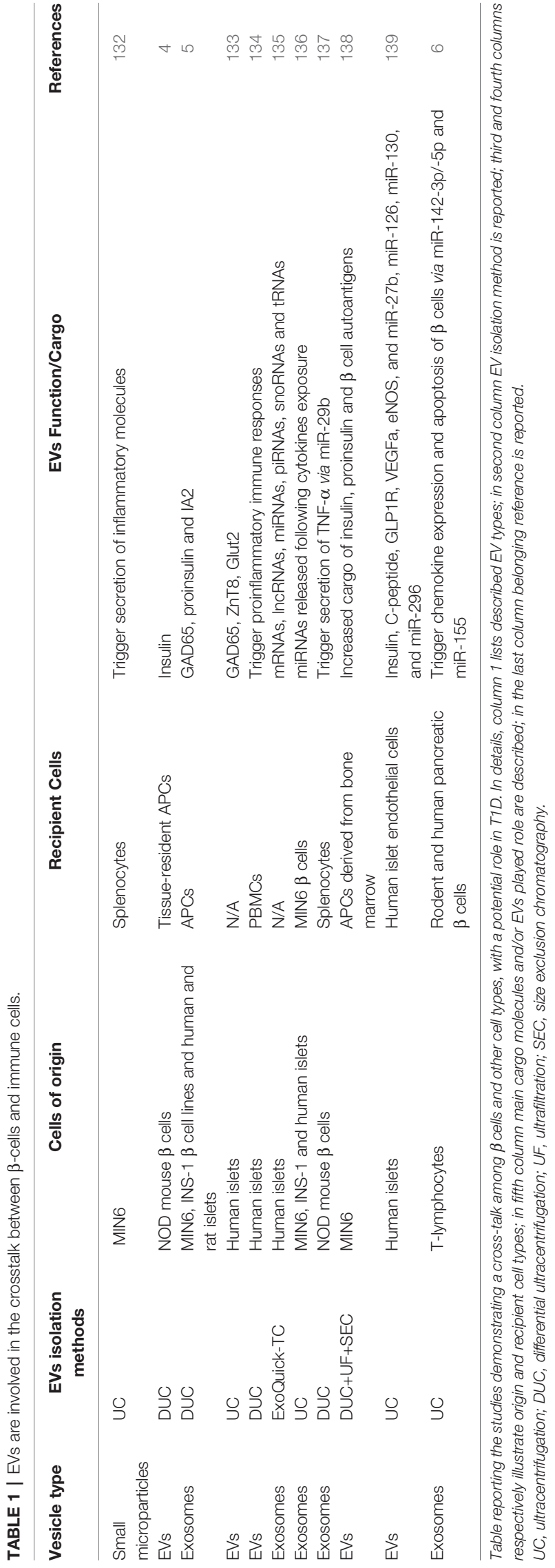

showed the presence of islet autoantigens (GAD65, proinsulin, and IA2) in EVs isolated from MIN6 and INS- $1 \beta$ cell lines supernatant as well as from those isolated from human and rat islets culture medium (5). The induction of ER stress by proinflammatory cytokines in rat islets increased EVs secretion. Of note, mouse islet EVs can be uptaken by APCs leading to their activation. Interestingly, APCs activation was increased when exposed to EVs derived from proinflammatory cytokines treated islets vs. non treated control samples, thus demonstrating that inflammatory stress induced EVs cargo molecules modulation as well.

The presence of GAD65 autoantigens in EVs released by human pancreatic islets was also confirmed by Hasilo and colleagues who were also able to detect the autoantigen $\mathrm{ZnT}$, as well as the $\beta$ cell glucose transporter 2 (Glut2) (133).

Human pancreatic islet EVs can be actively internalized by PBMCs, particularly by $\mathrm{CD} 14^{+}$cells and by $\mathrm{CD} 19^{+} \mathrm{B}$-cells. Of note, IL- 6 , TNF- $\alpha$ and IL- $1 \beta$ cytokines expression were significantly increased in $\mathrm{CD} 14^{+}$cells upon EVs internalization. Such inflammatory pathways triggering also involved the upregulation of IFN- $\gamma$, IL-4, and IL-17 expression in $\mathrm{CD}^{+} \mathrm{T}$ cells and a significant increase of $\mathrm{CD}^{+} 9^{+}$cell proliferation upon human islets EVs PBMCs exposure. Interestingly, both Th1 cytokines expression and $\mathrm{CD} 19^{+}$cells proliferation were further increased in T1D derived PBMCs exposed to human islets EVs. Additionally, human islets EVs are able to specifically activate memory $\mathrm{T}$ cells derived from T1D patients but not those from non-diabetic control subjects, as documented by a significant increase of CD69 MFI in both memory T-cells (CD4+CD45RO+CD45RA-CCR7-CD62L-) and B-cells (CD19+IgD-CD27+) observed in T1D PBMCs (134). Since memory B and T-cells activation upon EVs exposure is selective to T1D patients and not observed in nondiabetic controls, these results strongly suggest a pivotal role of EVs in antigen-specific responses.

These data demonstrate the role of EVs in the transfer of autoantigens, or other inflammation-relevant molecules, from islets to immune cells thus representing a novel mechanism of autoimmune reaction triggering in T1D pathogenesis.

As described previously, miRNAs and other RNA molecules are critical components of EVs cargo and could play a key role in the dialogue between pancreatic islets and immune cells (143). Notably, given their intrinsic regulatory function, the evaluation of miRNAs and other small non-coding RNAs enclosed in isletderived EVs is of particular relevance. In 2019, the group of Evans-Molina characterized the RNA content of exosomes secreted by in-vitro cultured human pancreatic islets (135). In this study, Krishnan and colleagues performed both total RNA and small RNA sequencing analysis of human pancreatic islets released exosomes pool, showing a prevalence of mRNA transcript, long non-coding RNAs and miRNAs. Of note, they highlighted the presence of additional small RNA species such as tRNA fragments and piRNAs, showing the high complexity of human islets exosomal RNAome. A critical question related to exosomal RNAome is about its potential alteration following stress stimuli typical of T1D, such as proinflammatory cytokines (IL-1 $\beta+$ IFN $\gamma$ ). Of interest, they found a total of 133 mRNAs, 




FIGURE 2 | Crosstalk between $\beta$ cells and immune cells through EVs. In T1D context, $\beta$ cells and immune cells tightly communicate each other. $\beta$ cells are subjected to glucotoxic and/or inflammatory stress and can release EVs containing specific miRNAs characterized by a GU-rich sequence (let-7a/b/c, miR-21 and miR-29a) which are transferred to resident Antigen Presenting Cells (APCs), where these miRNAs can bind to endosomal Toll Like Receptor 7 (TLR7) leading to the activation of inflammatory signals (140-142). Moreover, under inflammatory stress, $\beta$ cells secrete and transfer EVs to APCs. Such EVs can contain specific autoantigens such as insulin, IA2, ZNT8, GAD65 and proinsulin (5) thus leading to their transfer to APC which can present these antigens for adaptive immunity activation. Activated APC can also lead to CD4 ${ }^{+}$ T cells activation through two different mechanisms: (i) release of EVs containing insulin, IA2, ZNT8, GAD65 and proinsulin autoantigens (4), or (ii) release of EVs exposing MHC-II on their surface through which APCs present autoantigens to CD4 ${ }^{+}$T cells $(86,87)$, leading to autoreactive T cell activation and subsequent $\beta$ cell destruction. In T1D context, pancreatic islet-infiltrating T cells secrete a specific subpopulation of EVs carrying miR-142-3p/5p and miR-155 which can be transferred to $\beta$ cells; these miRNAs cause the upregulation of inflammatory molecules such as CCL2, CCL7 and CXCL10 leading to $\beta$ cell apoptosis (6).

31 lncRNAs, 19 miRNAs, 25 piRNAs, 8 snoRNAs, and 20 tRNAs as differentially expressed in EVs secreted from cytokines-treated human pancreatic islets respect to not-treated control samples. Among differentially expressed miRNAs in EVs released from human pancreatic islets in response to cytokines, Krishnan and colleagues identified miR-155-5p as the most upregulated miRNA, while miR-4485 was the most downregulated. Although such data cannot confirm the direct origin of EVs small RNAs content alterations from $\beta$-cells, they certainly indicate a global contribution of islet EVs to potential pathogenetic mechanisms and cell-cell communication pathways in T1D. As a matter of fact, other evidence previously showed that exosomal small RNAs cargo is profoundly shaped by proinflammatory stressors in $\beta$ cells. Importantly, exosomal miRNAs do not simply represent cellular miRNAs expression changes. Guay C. and colleagues demonstrated that MIN6 exosomal miRNAs are significantly different upon proinflammatory stress respect to untreated control and that specific miRNAs are preferentially released in exosomes only after cytokines exposure while others are selectively retained by the cells (136). Of interest, exosomes released from cytokines-treated MIN6 $\beta$ cells can be horizontally transferred to not stressed MIN6 cells, inducing the same type of apoptotic response and demonstrating also the transfer of exosomes among $\beta$ cells (136). A point of interest resides in the evaluation of the contribution of small RNAs transfer mediated by exosomes from $\beta$ cell to other cells. Salama and colleagues demonstrated that the exposure of splenocytes isolated from diabetes-prone NOD mice to $\beta$ cell-released exosomes is able to increase the synthesis and secretion of TNF- $\alpha$ (137); such effect was dependent on the presence of miR-29b within $\beta$ cell EVs. The inhibition of exosomal miR-29b reversed the TNF- $\alpha$ increase in splenocytes, thus demonstrating the role of exosomes-transferred miRNAs in the activation of immune cells toward a proinflammatory phenotype.

In the light of the high heterogenous pattern of vesicles secretion by cells of origin, an interesting aspect is the identification of molecules cargo associated to different types of vesicles secreted from the same cell. A recent study analyzed the entire spectrum of vesicle populations (apoptotic bodies, microvesicles and exosomes) secreted by MIN6 cells following the exposure to various stress conditions (proinflammatory stress, UV exposure, hypoxia) (138). Interestingly, the authors reported that proinflammatory stress is able to enhance all EVs 
population secretion, therefore, leading to an increased vesicles number. Most importantly, EVs released upon inflammatory stress exposure showed changes of cargo molecules respect to the physiologic ones. Of note, apoptotic bodies and exosomes convey not only a higher cargo of insulin, proinsulin, and $\beta$ cell autoantigens upon stresses but also an increased amount of TLR binding miRNAs (e.g., GU-rich miRNAs let-7a/b/c, miR21, and miR-29a). TLR binding miRNAs have a specific sequence which can be recognized as a DAMP by endosomal localized TLRs, thus triggering the downstream associated immune signalling. Specifically, Toll-like Receptor 7 (TLR-7) can recognize these EVs-miRNAs thus playing an essential role in the activation of autoimmune processes (140-142). As a matter of fact, EVs secreted from MIN6 cells exposed to inflammatory stress are able to activate primary APCs derived from bone marrow of NOD/ShiLtJ mice (138). Such mechanism is also partially driven by increased cytokines and chemokines cargo levels found in EVs upon MIN6 proinflammatory treatment respect to control. Among them, monocyte chemoattract protein-1 (MCP-1) is one of the most hyperexpressed (138).

Interestingly, it should be noted that human pancreatic islets communicate via EVs also with other non-immune cell types. Indeed, Figliolini and colleagues showed that pancreatic islets secreted EVs can be uptaken by local endothelial cells mediating the transfer of several mRNAs (e.g., VEGF and NOS) and miRNAs (e.g., miR-126a, miR-27a), thereby modulating endothelial cells proliferation and function (139). Since human islet endothelial cells represent a pivotal interface directly interacting with immune-cells (144) and playing a critical role in the early phase of T1D by increasing the expression of surface leucocyte-homing receptors, we can speculate that the alteration of pancreatic islet EVs content in response to proinflammatory stressors may indirectly induce endothelial cell dysfunction and, in turn, putative deregulation of their interaction with immune cells. Overall, these studies demonstrated that the specific cargo of different populations of EVs secreted by $\beta$ cells can activate several immune cell types, thus rendering insulin-producing cells visible and exposed to immune-mediated destruction and leading to the exacerbation of inflammation and autoimmune diabetes.

\section{EVs From Immune Cells to Pancreatic $\beta$ Cells}

Immune cells are able to secrete unique EVs populations which can be transferred to other cell types, including insulinproducing $\beta$ cells. A seminal study by Guay and colleagues, reported that three miRNAs, namely miR-142-3p, miR-142-5p, and miR-155, are particularly enriched in T lymphocytes of 8 weeks NOD mice with respect to mouse pancreatic islets (145). Importantly, authors also demonstrated that NOD mice $\mathrm{CD}^{+} /$ $\mathrm{CD}^{-} 5^{-} \mathrm{T}$ lymphocytes specifically release a population of exosomes enriched of miR-142-3p, miR-142-5p, and miR-155 (6), and that this release is independent from cytokines secreted by infiltrating immune cells, thus hypothesizing that $\mathrm{T}$ cells could be able to transfer a specific population of EVs to $\beta$ cells. In order to test this hypothesis, dispersed murine islets were treated with exosomes isolated from $\mathrm{T}$ cells of NOD mice (exoNOD), and MIN6 cells were subjected to EVs isolated from Jurkat human $\mathrm{T}$ cell line (exoT). In both cases they observed an increased expression of miR-142-3p/-5p, and miR155 , thus confirming that these miRNAs are actively transferred from $\mathrm{T}$ lymphocytes to $\beta$ cells in autoimmune diabetes. Importantly, a higher apoptotic rate was observed in both dispersed mouse and human islet cells treated with exosomes secreted by activated primary human T cells (exo$\mathrm{hT}$ ), thus indicating a detrimental role for this set of miRNA in $\beta$ cells.

The pro-apoptotic effect of exosomal miR-142-3p/5p and miR-155 is potentially due to their ability to induce the upregulation of several cytokines (CCL2, CCL7, and CXCL10) in murine and human pancreatic islets $\beta$ cells. As a matter of fact, the in vitro inhibition of these three miRNAs was able to reduce apoptosis rate induced by exoT in primary rat islet cells. The same protective effect was also observed in 4-week-old NOD mice upon inhibition of miR-142-3p/5p and miR-155-5p through adenoviral associated miRNA sponges treatment. Of note, the injection of miRNA sponges reduced autoimmune diabetes development rate (10\% in AAV-treated mice vs. $60 \%$ of not treated mice) via a significant decrease of inflammation and insulitis primarily driven by a specific reduction of CXCL10 protein levels in pancreatic islet $\beta$ cells.

\section{EVs as a Potential Source of Novel Biomarkers in T1D}

EVs' secretion and their presence in many biological fluids prompted the scientific community to investigate their role as novel biomarkers (146). Indeed, circulating EVs number and content could be altered in several disease conditions, thus representing not only a vehicle of communication and interaction between different cell types but also a possible source of biomarkers (147).

It is well established that the underlying autoimmune process of T1D occurs long before the clinical onset. Efficient biomarkers for the early identification and stratification of high-risk T1D subjects are still lacking (148). Of note, numerous studies explored the potential usefulness of whole plasma/serum miRNAs analysis to detect novel biomarkers of T1D (149152). However, the detection of miRNAs associated to different plasma/serum components could be the key to uncover novel and more specific biomarkers. In such context, EVs may represent an optimal source of novel and specific biomarkers. As a matter of fact, different studies demonstrated that EVs' size, number, and enclosed cargo are altered in several diseases, including T1D (153).

In an effort to characterize circulating EVs of T1D patients, Garcia-Contreras and colleagues analyzed EVs isolated using ultracentrifugation approach from plasma of long-standing T1D patients ( 25 years disease duration) and age- and gendermatched non diabetic subjects. They observed reduced EVs 
concentration and increased average size in plasma of T1D respect to CTR subjects (148). Moreover, the same authors found an altered expression of several miRNAs in circulating EVs isolated from T1D subjects. In details, miR-16-5p, miR302d-3p, miR-378e, miR-570-3p, miR-574-5p, and miR-579 were downregulated, while miR-25-3p was upregulated in EVs from plasma of T1D subjects respect to controls.

In a more recent work, Tesovnik et al. investigated the potential alterations of plasma EVs miRNAs cargo in children with newly diagnosed T1D ( $<6$ months) (nT1D) and in T1D young adults subjects ( $\max 10$ years of disease duration, 10yT1D) in comparison to healthy subjects. Following EVs small RNAs sequencing, the authors found a higher expression of miR122-5p and miR-192-5p in nT1D cohort compared to controls, as well as the differential expression of several miRNAs in nT1D versus $10 y-T 1 D$, namely the downregulation of miR-193b-5p, miR-195-3p, miR-122-5p, and miR-445-5p and the upregulation of miR-21-5p. Furthermore, miR-195-3p and miR-455-5p were both downregulated while miR-185-5p expression was upregulated in 10y-T1D vs control subjects (154).

The importance to distinguish miRNAs enriched in EVs fraction respect to whole biofluid (serum or plasma) was mainly highlighted in a work published by Lakhter and colleagues (155). In details, they reported a significant upregulation of miR-21-5p in EVs secreted by MIN6 murine $\beta$ cell line, EndoC- $\beta \mathrm{H} 1$ and human pancreatic islets treated with a proinflammatory cytokines mix. Of note, miR-21-5p was increased in whole serum as well as in serum-EVs from NOD diabetic mice respect to control mice. In T1D subjects, the expression of miR-21-5p was discordant between whole serum and serum-isolated EVs; indeed, miR-21-5p resulted significantly reduced in whole serum T1D respect to controls while it was upregulated in serum-isolated EVs, thus demonstrating that analyzing miRNAs expression by distinguishing different fractions (EVs, ribonucleoproteins, lipoproteins, etc.) could be of critical importance in order to identify potential circulating biomarkers of several diseases, including T1D (155).

Another important work published in 2019 by Mirza and colleagues, showed that several miRNAs can be differentially expressed in the EVs derived from breast milk of T1D mothers respect to non diabetic ones. Particularly, they detected a significant hyperexpression of four miRNAs, namely miR-4497, miR-3178, miR-1246, and miR-133a-3p. Importantly, in vitro overexpression of miR-4497 and miR-3178 in macrophages resulted in their activation, thus consequently stimulating the secretion of cytokines (TNF- $\alpha$ and IL-1 $\beta$ ) (156). Importantly, since it has been previously demonstrated that newborn food intake could affect the potential future development of T1D $(157,158)$, it could be useful to further investigate the potential role of these breast milk EVs miRNAs in children breastfed by T1D mothers.

Overall, these data demonstrate that the altered expression of miRNAs in EVs of T1D subjects, both recent onset and long standing, could represent valid biomarkers for the prediction and the diagnosis of T1D. However, further studies are needed to better characterize EVs obtained from T1D patients in order to use them as biomarkers.

\section{EVs AS INNOVATIVE THERAPEUTIC TOOLS FOR IMMUNE SYSTEM MODULATION AND T1D}

EVs have recently emerged as novel and attractive therapeutic tools in immune therapy, regenerative medicine and drug delivery (159). A growing number of preclinical and clinical studies investigated EVs therapeutic applications in a wide range of diseases including T1D (Table 2) (146).

The most investigated source of EVs as therapeutic tools aimed at immune modulation are mesenchymal stem cells (MSCs) (172). As a matter of fact, MSCs are extensively studied for their regenerative and anti-inflammatory roles (173). The therapeutic properties of MSCs have been largely attributed to their differentiation and self-renewal ability, upon specific environmental stimuli, as well as to their immunomodulatory actions, both toward innate and adaptive immunity $(172,174,175)$. However, increasing evidence showed that EVs are responsible of most of the beneficial effects of MSCsbased therapy, as demonstrated by the appearance of regenerative effects following administration of MSCs supernatant in damaged tissues (174-176). EVs efficiently mimic the biological activity of parental MSCs and exhibit the same surface receptors, signaling and cell adhesion molecules or associated antigens of parental cells thus representing an interesting cell-free alternative to MSC-based therapy $(172,174)$. The use of MSC-EVs therapy, although investigated in a small number of clinical trials, showed several advantages over MSC-based therapy, such as higher safety profile, lower immunogenicity, better biodistribution, no need for engraftment, ability to evade from clearance by reticuloendothelial system, reduced systemic and off-targets side effects, and the capacity to cross biological barriers, while avoiding risks of oncogenesis, embolism, and immune rejection $(172,173,176-$ 178). Indeed, several promising results in preclinical studies have kicked off numerous clinical trials on the therapeutic use of EVs in several diseases from autoimmune and inflammatory diseases to cancer.

MSC-EVs are reported to induce an imbalance in the secretory pattern of cytokines from immune cells, in favor of anti-inflammatory ones, while inhibiting the secretion of proinflammatory cytokines $(172,174)$. Of note, MSC-EVs effects on dendritic cells (DCs) seems to be largely mediated by miRNAs (i.e. miR-21-5p, miR-142-3p, miR-223-3p, and miR126-3p), resulting in the inhibition of maturation, and consequently to an impairment of antigen uptake and antigen presentation capacity (179). Moreover, MSC-EVs stimulate macrophages M2 polarization meanwhile reducing recruitment, activation, and M1 polarization of macrophages and monocytes (180, 181). Furthermore, MSC-EVs inhibit the activation and proliferation of $\mathrm{T}$ and B lymphocytes (182), increase the ratio of Treg cells on effector $\mathrm{T}$ cells and enhance the function of Treg (171), inhibit maturation of B cells and the consequent immunoglobulin secretion. In addition, MSC-EVs is also able to re-induce self-tolerance through the transfer of antiinflammatory and tolerogenic molecules into autoreactive $\mathrm{T}$ cells, promoting generation of Tregs and apoptosis of 
TABLE 2 | EVs and therapeutic applications in T1D or in T1D complications.

Cells of Origin EVs cargo

Target organ

Growth factor, transforming growth factor- $\beta 1$,

angiogenin and bone morphogenetic protein-7

Bone-marrow stromal cells (BMSCs)

Human umbilical cord blood-derived miR-145

$\mathrm{N} / \mathrm{A}$

Reduction of the urine volume and urinary microalbumin excretion; prevention of

160

podocyte and tubular epithelial cell apoptosis in diabetic rats.

Brain Improved functional outcome and promoted neurorestorative effects

Skin Enhancement of Angiogenesis Through Erk1/2 Signaling

Skin Enhancement of the proliferation, migration and tube formation of vascular

endothelial cells

Brain Improvement of cognitive impairments by repairing damage neurons and astrocytes

Improvement of cardiac function and angiogenesis

Attenuation of renal fibrosis

Activation of diabetic dermal fibroblast; induction

chymal stem cells

let-7c

Kidney

Human circulate fibrocyte

HSP90-Alpha; miR-126; miR-130a; miR-132; miR-

Mouse serum

Human bone marrow mesenchymal

stem cells

124a; miR-125b: miR-21

miR-106b-5p and miR-222-3p

$\mathrm{N} / \mathrm{A}$

Endocrine pancreas Improvement of hyperglycaemia via pancreatic beta cell proliferation

Endocrine pancreas Inhibition of immune rejection

Enhancement of neo-angiogenesis of human pancreatic islets

$\begin{array}{ll}\text { Endocrine pancreas } & \text { Enhancement of neo-angiogenesis of human pancreatic islets } \\ \text { Spleen } & \text { Increase of regulatory T-cell population and their products without a change in the }\end{array}$ proliferation index of Iymphocyte

Adipose tissue-derived mesenchymal $\quad$ NAA

miR-126 and miR-196

stem cells

Table reporting the potential therapeutic applications of EVs. In particular, we included: (i) Origin cells or biofluid from which vesicles are isolated; (ii) the main cargo of these vesicles; (iii) organ targeted by the specific EVs population; (iv) potential therapeutic function and/or mechanisms acted by released EVs. 
activated T cells (182). Taken together, these findings suggest that MSC-EVs directly influence the immune state of adaptive immune cells and promote an anti-inflammatory phenotype of antigen presenting cells (APCs) also inducing immunotolerance of $\mathrm{T}$ and $\mathrm{B}$ lymphocytes.

Although the use of MSC-EVs in autoimmune diseases therapy is still at early stages, several clinical trials are evaluating their efficacy and safety. As a matter of fact, a first study published by Rahman and colleagues in 2014 demonstrated the immunostimulatory effect of EVs released by mesenchymal stem cells derived from in vitro culture of 8-weekold NOD mice pancreatic islets. Indeed, authors demonstrated that vesicles released by these MSCs and injected into 1 week old NOD mice are able to enhance inflammatory reactions, resulting in the increase of cytokines release (IL-6, IFN- $\gamma$, TNF- $\alpha$, and MCP-1), stimulation of surface TLRs and other innate receptors as well as increased $\mathrm{B}$ cells proliferation rate. Therefore, authors hypothesized that MSC-EVs could potentially contain and transport immunostimulatory autoantigens, leading to enhanced immune response (183).

However, more recent evidence suggest therapeutic efficacy of EVs in T1D, through immunomodulatory effects (171), protection of pancreatic islets from autoimmune targeting, and consequent slowdown of disease progression $(160,161,163-$ 167). Furthermore, adipose tissue MSCs-derived EVs were proved to reduce hyperglycaemia and islet degeneration in mice with autoimmune diabetes (168); in addition, the levels of IL-17 and TNF- $\alpha$ were significantly decreased while IL-4, IL-10, and TGF- $\beta$ levels, as well as Treg number are significantly increased in spleen of EV-treated mice (171).

Of note, EVs could represent a promising tool to overcome possible failure of islet transplantation due to the immune rejection and loss of function of transplanted islets (169). Indeed, MSC-EVs administration alongside with islet transplantation, is able to improve islet functions simultaneously inducing transplant tolerance by enhancing Treg function (184). In accordance with these observations, MSC-EVs treatment resulted in increased graft survival and normalized blood glucose levels in T1D mice (178).

More recently, EVs have also emerged as vectors of bioactive molecules, given their intrinsic stability, biocompatibility, and target homing ability. Several studies investigated whether EVs could deliver anti-inflammatory compounds in central nervous system $(185,186)$. Indeed, purified EVs can be loaded with therapeutically active cargo molecules ex vivo, e.g., through electroporation of small molecules into EVs or, alternatively, the molecules of interest can be incorporated in EVs in vivo, during vesicles biogenesis (187).

Despite these encouraging evidence, clinical translation of EVs has been hindered by challenges in isolation, purification, and high-yield production. Dose-finding is also critical for clinical application, since EVs effects seemed to be dosedependent (188). Moreover, despite quality control and manufacturing practice improvement, EVs heterogeneity is still difficult to eliminate. With the aim to bypass these limitations, researchers have focused on synthetic EVs production, such as liposomes - the most biocompatible and least toxic artificial vesicles created from cholesterol and phospholipids and cholesterol-and biomimetic nanoparticles-which are hybrid nanostructures coated with exosomes-like membranes with desired targeting or functional characteristics (189). Exosomemimetic nanosystems showed important advantages in production efficiency and functionality (190). Another critical aspect in the clinical use of EVs relates to the integrity of the cargo, which could be reduced/damaged by common loading methods, thus making it crucial to develop novel loading efficiency evaluation systems $(191,192)$.

TABLE 3 | Outstanding questions on T1D and EVs: how to push the field forward?

\section{Key Question}

Which is the best methodology to isolate a pure fraction of EVs from cell culture supernatant and plasma?

Are there markers characterizing exosomes released by human $\beta$ cells? If so, can we specifically isolate them from cell culture supernatant or plasma samples?

Which set(s) of stress stimuli drives differential EVs release and content secreted from primary human $\beta$-cells?

Can we use engineered EVs to target $\beta$-cells or specific immune cell subsets in order to protect $\beta$ cells or to restore immune tolerance in T1D?

\section{Comments}

Absolute purification and isolation of EVs from their origin biological fluids, is an unrealistic goal at present. Each method and approach has advantages, as well as disadvantages and each of this influences the amount, type and purity of recovered EVs. It is important to choose based on the downstream applications and scientific questions of planned experiments.

It has been reported that exosomes derived from $\beta$-cells are enriched of a cargo composed by different specific $\beta$ cells markers (insulin and proinsulin); nevertheless, no surface exosomal marker specific for $\beta$-cells has been identified yet.

However, as future goal, a potential approach could be that of performing a proteomic profile on exosomes isolated from culture medium of pure human $\beta$-cell in order to identify a specific $\beta$-cell membrane marker on exosomes surface.

It has been reported that proinflammatory cytokines mix induces an increase of miR-21-5p in exosomes derived from Endoc $\beta-\mathrm{H} 1$ and human islets, without significant differences in term of quantity and size of exosomes, suggesting a selective enrichment of EVs miR-21-5p in response to inflammatory stress. Moreover, Krishnan et al. demonstrated that exosomes released from human pancreatic islets treated with IL-1 $\beta$ and IFN $\gamma$ showed differential expression of several RNAs species, with respect to untreated human islets. However a wide range of stress test on primary islets are still missing and require further studies.

EVs have also emerged as vectors of bioactive molecules, given their intrinsic stability, biocompatibility and target homing ability. Cantaluppi et al. demonstrated that EVs released by endothelial progenitor cells carried the proangiogenic miR-126 and miR-296 that enhance neoangiogenesis of human pancreatic islets thus improving their function. A potential mechanism to improve $\beta$-cell function may reside in the engineering of endothelial progenitor-like EVs overexpressing miR-126 and miR-296 in order to ameliorate islet function.
References

193, 194

4,5

135,155 


\section{CONCLUDING REMARKS}

EVs are involved in multiple mechanisms of immune system function and regulation through the transfer of bioactive cargo molecules which include cytokines, chemokines, lipids, metabolites, and small RNAs. The alterations of EVs mediated cell-cell communication mechanisms have been shown to be critical in multiple autoimmune diseases including T1D. Importantly, EVs have been shown to be involved in the bidirectional crosstalk between pancreatic $\beta$ cells and immune cells, thus representing an interesting mechanism to be further studied during the pathogenesis of T1D.

EVs have been also explored as a novel potential source of disease biomarkers. Indeed, multiple small RNAs have been found altered exclusively in circulating exosomal component; such results indicate the needs to differently fractionate plasma/ serum components [EVs, ribonucleoproteins (e.g., AGOs family), lipoprotein particles], in order to discover novel disease biomarkers, whose alteration can be hindered by a dilution effect when analyzing samples as a whole. It should be underlined the urgent need for standardization of isolation and purification of circulating EVs, quality control checks, and storage protocols, as well as the development of sensitive and scalable downstream methodologies to analyze EVs content, including small RNAs, proteins, and metabolites. Moreover, additional studies about the role and functionality of EVs cargo, and in particular on the ability of non-coding RNAs to further regulate cellular processes into recipient cells, are needed in order to shed light onto their mechanisms and functions.

Multiple critical questions surrounding EVs and T1D research (see Table 3) are still requiring adequate studies in order to move forward to large-scale clinical application of EVs, as well as to define rigorous criteria for quality control and standardized strategies for quantification and characterization of EVs. Nonetheless, EVs represent a relatively novel and still largely unexplored research field encompassing biomarkers,

\section{REFERENCES}

1. Atkinson MA, Eisenbarth GS, Michels AW. Type 1 Diabetes. Lancet (2014) 383(9911):69-82. doi: 10.1016/S0140-6736(13)60591-7

2. Nigi L, Maccora C, Dotta F, Sebastiani G. From Immunohistological to Anatomical Alterations of Human Pancreas in Type 1 Diabetes: New Concepts on the Stage. Diabetes Metab Res Rev (2020) 36(4):e3264. doi: 10.1002/dmrr.3264

3. Insel R, Dutta S, Hedrick J. Type 1 Diabetes: Disease Stratification. BioMed Hub (2017) 2(Suppl 1):111-26. doi: 10.1159/000481131

4. Vomund AN, Zinselmeyer BH, Hughes J, Calderon B, Valderrama C, Ferris ST, et al. Beta Cells Transfer Vesicles Containing Insulin to Phagocytes for Presentation to T Cells. Proc Natl Acad Sci USA (2015) 112(40):E5496-502. doi: 10.1073/pnas.1515954112

5. Cianciaruso C, Phelps EA, Pasquier M, Hamelin R, Demurtas D, Alibashe Ahmed M, et al. Primary Human and Rat $\beta$-Cells Release the Intracellular Autoantigens GAD65, Ia-2, and Proinsulin in Exosomes Together With Cytokine-Induced Enhancers of Immunity. Diabetes (2017) 66(2):460-73. doi: $10.2337 / \mathrm{db} 16-0671$

6. Guay C, Kruit JK, Rome S, Menoud V, Mulder NL, Jurdzinski A, et al. Lymphocyte-Derived Exosomal Micrornas Promote Pancreatic $\beta$ Cell Death and May Contribute to Type 1 Diabetes Development. Cell Metab (2019) 29 (2):348-61.e6. doi: 10.1016/j.cmet.2018.09.011 pathogenetic and therapeutic area in T1D research, thus strongly requiring focused attention by the research community.

\section{AUTHOR CONTRIBUTIONS}

GEG, DF, CF, LN, CM, GL, and NB: writing and drafting the manuscript. GS and FD: manuscript writing, drafting and revising. All authors contributed to the article and approved the submitted version.

\section{FUNDING}

The work is supported by the Innovative Medicines Initiative 2 (IMI2) Joint Undertaking under grant agreement no. 115797INNODIA and no. 945268 INNODIA HARVEST. This joint undertaking receives support from the Union's Horizon 2020 research and innovation programme and EFPIA, JDRF, and the Leona M. and Harry B. Helmsley Charitable Trust. This work is also supported by PON "Ricerca e Innovazione" 2014-2020 (ARS01_01270-IDF SHARID-Innovative Devices For SHAping the RIsk of Diabetes). FD was supported by the Italian Ministry of University and Research (2017KAM2R5_003) and by Italian ministry of Health (PROMETEO). GS was supported by the Italian Ministry of University and Research (201793XZ5A_006) and by Italian Ministry of Health Ricerca Finalizzata 2018" (GR2018-12365577).

\section{ACKNOWLEDGMENTS}

The secretarial help of Maddalena Prencipe and Alessandra Mechini was greatly appreciated.

7. Théry C, Zitvogel L, Amigorena S. Exosomes: Composition, Biogenesis and Function. Nat Rev Immunol (2002) 2(8):569-79. doi: 10.1038/nri855

8. van Niel G, D'Angelo G, Raposo G. Shedding Light on the Cell Biology of Extracellular Vesicles. Nat Rev Mol Cell Biol (2018) 19(4):213-28. doi: $10.1038 / \mathrm{nrm} .2017 .125$

9. Kalluri R, LeBleu VS. The Biology, Function, and Biomedical Applications of Exosomes. Science (2020) 367(6478). doi: 10.1126/science.aau6977

10. Gould SJ, Raposo G. As We Wait: Coping With an Imperfect Nomenclature for Extracellular Vesicles. J Extracell Vesicles (2013) 2. doi: 10.3402/jev.v2i0.20389

11. Cocucci E, Meldolesi J. Ectosomes and Exosomes: Shedding the Confusion Between Extracellular Vesicles. Trends Cell Biol (2015) 25(6):364-72. doi: 10.1016/j.tcb.2015.01.004

12. Meldolesi J. Exosomes and Ectosomes in Intercellular Communication. Curr Biol (2018) 28(8):R435-44. doi: 10.1016/j.cub.2018.01.059

13. Cocucci E, Meldolesi J. Ectosomes. Curr Biol (2011) 21(23):R940-1. doi: 10.1016/j.cub.2011.10.011

14. Choi D-S, Kim D-K, Kim Y-K, Gho YS. Proteomics, Transcriptomics and Lipidomics of Exosomes and Ectosomes. Proteomics (2013) 13(10-11):155471. doi: 10.1002/pmic.201200329

15. Mathieu M, Martin-Jaular L, Lavieu G, Théry C. Specificities of Secretion and Uptake of Exosomes and Other Extracellular Vesicles for Cell-to-Cell Communication. Nat Cell Biol (2019) 21(1):9-17. doi: 10.1038/s41556-0180250-9 
16. Bebelman MP, Smit MJ, Pegtel DM, Baglio SR. Biogenesis and Function of Extracellular Vesicles in Cancer. Pharmacol Ther (2018) 188:1-11. doi: 10.1016/j.pharmthera.2018.02.013

17. Kalluri R. The Biology and Function of Exosomes in Cancer. J Clin Invest (2016) 126(4):1208-15. doi: 10.1172/JCI81135

18. Kowal J, Tkach M, Théry C. Biogenesis and Secretion of Exosomes. Curr Opin Cell Biol (2014) 29:116-25. doi: 10.1016/j.ceb.2014.05.004

19. Rajagopal C, Harikumar KB. The Origin and Functions of Exosomes in Cancer. Front Oncol (2018) 8:66. doi: 10.3389/fonc.2018.00066

20. Poteryaev D, Datta S, Ackema K, Zerial M, Spang A. Identification of the Switch in Early-to-Late Endosome Transition. Cell (2010) 141(3):497-508. doi: 10.1016/j.cell.2010.03.011

21. Hanson PI, Cashikar A. Multivesicular Body Morphogenesis. Annu Rev Cell Dev Biol (2012) 28:337-62. doi: 10.1146/annurev-cellbio-092910-154152

22. Kahlert C, Kalluri R. Exosomes in Tumor Microenvironment Influence Cancer Progression and Metastasis. J Mol Med (2013) 91(4):431-7. doi: 10.1007/s00109-013-1020-6

23. Luzio JP, Gray SR, Bright NA. Endosome-Lysosome Fusion. Biochem Soc Trans (2010) 38(6):1413-6. doi: 10.1042/BST0381413

24. Mathivanan S, Fahner CJ, Reid GE, Simpson RJ. ExoCarta 2012: Database of Exosomal Proteins, RNA and Lipids. Nucleic Acids Res (2012) 40(Database issue):D1241-4. doi: 10.1093/nar/gkr828

25. Simpson RJ, Kalra H, Mathivanan S. ExoCarta as a Resource for Exosomal Research. J Extracell Vesicles (2012) 1. doi: 10.3402/jev.v1i0.18374

26. Kalra H, Simpson RJ, Ji H, Aikawa E, Altevogt P, Askenase P, et al. Vesiclepedia: A Compendium for Extracellular Vesicles With Continuous Community Annotation. PloS Biol (2012) 10(12):e1001450. doi: 10.1371/ journal.pbio. 1001450

27. Keerthikumar S, Chisanga D, Ariyaratne D, Al Saffar H, Anand S, Zhao K, et al. Exocarta: A Web-Based Compendium of Exosomal Cargo. J Mol Biol (2016) 428(4):688-92. doi: 10.1016/j.jmb.2015.09.019

28. Perez-Hernandez D, Gutiérrez-Vázquez C, Jorge I, López-Martín S, Ursa A, Sánchez-Madrid F, et al. The Intracellular Interactome of TetraspaninEnriched Microdomains Reveals Their Function as Sorting Machineries Toward Exosomes. J Biol Chem (2013) 288(17):11649-61. doi: 10.1074/ jbc.M112.445304

29. Hegmans JPJJ, Bard MPL, Hemmes A, Luider TM, Kleijmeer MJ, Prins J-B, et al. Proteomic Analysis of Exosomes Secreted by Human Mesothelioma Cells. Am J Pathol (2004) 164(5):1807-15. doi: 10.1016/S0002-9440(10) 63739-X

30. Simpson RJ, Jensen SS, Lim JWE. Proteomic Profiling of Exosomes: Current Perspectives. Proteomics (2008) 8(19):4083-99. doi: 10.1002/pmic. 200800109

31. Gouin K, Peck K, Antes T, Johnson JL, Li C, Vaturi SD, et al. A Comprehensive Method for Identification of Suitable Reference Genes in Extracellular Vesicles. J Extracell Vesicles (2017) 6(1):1347019. doi: 10.1080/ 20013078.2017.1347019

32. Karlsen TA, Aae TF, Brinchmann JE. Robust Profiling of microRNAs and isomiRs in Human Plasma Exosomes Across 46 Individuals. Sci Rep (2019) 9 (1):19999. doi: 10.1038/s41598-019-56593-7

33. Fallen S, Baxter D, Wu X, Kim T-K, Shynlova O, Lee MY, et al. Extracellular Vesicle RNAs Reflect Placenta Dysfunction and are a Biomarker Source for Preterm Labour. J Cell Mol Med (2018) 22(5):2760-73. doi: 10.1111/ jcmm. 13570

34. Ghai V, Kim T-K, Etheridge A, Nielsen T, Hansen T, Pedersen O, et al. Extracellular Vesicle Encapsulated MicroRNAs in Patients With Type 2 Diabetes are Affected by Metformin Treatment. J Clin Med (2019) 8(5):617. doi: $10.3390 / \mathrm{jcm} 8050617$

35. Ebrahimkhani S, Vafaee F, Hallal S, Wei H, Lee MYT, Young PE, et al. Deep Sequencing of Circulating Exosomal microRNA Allows non-Invasive Glioblastoma Diagnosis. NPJ Precis Oncol (2018) 2:28. doi: 10.1038/ s41698-018-0071-0

36. Martínez-González E, Brochado-Kith Ó, Gómez-Sanz A, Martín-Carbonero L, Jimenez-Sousa MÁ, Martínez-Román P, et al. Comparison of Methods and Characterization of Small RNAs From Plasma Extracellular Vesicles of HIV/HCV Coinfected Patients. Sci Rep (2020) 10(1):11140. doi: 10.1038/ s41598-020-67935-1
37. Colombo M, Moita C, van Niel G, Kowal J, Vigneron J, Benaroch P, et al. Analysis of ESCRT Functions in Exosome Biogenesis, Composition and Secretion Highlights the Heterogeneity of Extracellular Vesicles. J Cell Sci (2013) 126(Pt 24):5553-65. doi: 10.1242/jcs. 128868

38. Hurley JH. Escrts are Everywhere. EMBO J (2015) 34(19):2398-407. doi: 10.15252/embj.201592484

39. Stoorvogel W. Resolving Sorting Mechanisms Into Exosomes. Cell Res (2015) 25(5):531-2. doi: 10.1038/cr.2015.39

40. Juan T, Fürthauer M. Biogenesis and Function of ESCRT-dependent Extracellular Vesicles. Semin Cell Dev Biol (2018) 74:66-77. doi: 10.1016/ j.semcdb.2017.08.022

41. Hurley JH, Odorizzi G. Get on the Exosome Bus With ALIX. Nat Cell Biol (2012) 14(7):654-5. doi: 10.1038/ncb2530

42. Gatta AT, Carlton JG. The ESCRT-machinery: Closing Holes and Expanding Roles. Curr Opin Cell Biol (2019) 59:121-32. doi: 10.1016/ j.ceb.2019.04.005

43. Henne WM, Stenmark H, Emr SD. Molecular Mechanisms of the Membrane Sculpting ESCRT Pathway. Cold Spring Harb Perspect Biol (2013) 5(9): a016766. doi: 10.1101/cshperspect.a016766

44. Larios J, Mercier V, Roux A, Gruenberg J. ALIX- and ESCRT-III-dependent Sorting of Tetraspanins to Exosomes. J Cell Biol (2020) 219(3):e201904113. doi: $10.1083 /$ jcb. 201904113

45. Bissig C, Gruenberg J. ALIX and the Multivesicular Endosome: ALIX in Wonderland. Trends Cell Biol (2014) 24(1):19-25. doi: 10.1016/j.tcb.2013.10.009

46. Willms E, Johansson HJ, Mäger I, Lee Y, Blomberg KEM, Sadik M, et al. Cells Release Subpopulations of Exosomes With Distinct Molecular and Biological Properties. Sci Rep (2016) 6:22519. doi: 10.1038/srep22519

47. Kenific CM, Zhang H, Lyden D. An Exosome Pathway Without an ESCRT. Cell Res (2020) 31:105-6. doi: 10.1038/s41422-020-00418-0

48. Wei D, Zhan W, Gao Y, Huang L, Gong R, Wang W, et al. RAB31 Marks and Controls an ESCRT-independent Exosome Pathway. Cell Res (2020) 31:157177. doi: 10.1038/s41422-020-00409-1

49. Clayton A, Turkes A, Navabi H, Mason MD, Tabi Z. Induction of Heat Shock Proteins in B-cell Exosomes. J Cell Sci (2005) 118(Pt 16):3631-8. doi: $10.1242 /$ jcs. 02494

50. Reddy VS, Madala SK, Trinath J, Reddy GB. Extracellular Small Heat Shock Proteins: Exosomal Biogenesis and Function. Cell Stress Chaperones (2018) 23(3):441-54. doi: 10.1007/s12192-017-0856-z

51. Stuffers S, Sem Wegner C, Stenmark H, Brech A. Multivesicular Endosome Biogenesis in the Absence of Escrts. Traffic (2009) 10(7):925-37. doi: 10.1111/j.1600-0854.2009.00920.x

52. Jeppesen DK, Fenix AM, Franklin JL, Higginbotham JN, Zhang Q, Zimmerman LJ, et al. Reassessment of Exosome Composition. Cell (2019) 177(2):428-45.e18. doi: 10.1016/j.cell.2019.02.029

53. van Niel G, Charrin S, Simoes S, Romao M, Rochin L, Saftig P, et al. The Tetraspanin CD63 Regulates ESCRT-independent and -Dependent Endosomal Sorting During Melanogenesis. Dev Cell (2011) 21(4):708-21. doi: 10.1016/j.devcel.2011.08.019

54. Escola JM, Kleijmeer MJ, Stoorvogel W, Griffith JM, Yoshie O, Geuze HJ. Selective Enrichment of Tetraspan Proteins on the Internal Vesicles of Multivesicular Endosomes and on Exosomes Secreted by Human BLymphocytes. J Biol Chem (1998) 273(32):20121-7. doi: 10.1074/ jbc.273.32.20121

55. Ostrowski M, Carmo NB, Krumeich S, Fanget I, Raposo G, Savina A, et al. Rab27a and Rab27b Control Different Steps of the Exosome Secretion Pathway. Nat Cell Biol (2010) 12(1):19-30; sup pp 1. doi: 10.1038/ncb2000

56. Chevillet JR, Kang Q, Ruf IK, Briggs HA, Vojtech LN, Hughes SM, et al. Quantitative and Stoichiometric Analysis of the microRNA Content of Exosomes. Proc Natl Acad Sci USA (2014) 111(41):14888-93. doi: 10.1073/pnas.1408301111

57. Valadi H, Ekström K, Bossios A, Sjöstrand M, Lee JJ, Lötvall JO. ExosomeMediated Transfer of mRNAs and microRNAs is a Novel Mechanism of Genetic Exchange Between Cells. Nat Cell Biol (2007) 9(6):654-9. doi: $10.1038 /$ ncb1596

58. Cha DJ, Franklin JL, Dou Y, Liu Q, Higginbotham JN, Demory Beckler M, et al. KRAS-Dependent Sorting of miRNA to Exosomes. Elife (2015) 4: e07197. doi: 10.7554/eLife.07197 
59. Cheng L, Sharples RA, Scicluna BJ, Hill AF. Exosomes Provide a Protective and Enriched Source of miRNA for Biomarker Profiling Compared to Intracellular and Cell-Free Blood. J Extracell Vesicles (2014) 3:v3.23743. doi: 10.3402/jev.v3.23743

60. Srinivasan S, Duval MX, Kaimal V, Cuff C, Clarke SH. Assessment of Methods for Serum Extracellular Vesicle Small RNA Sequencing to Support Biomarker Development. J Extracell Vesicles (2019) 8(1):1684425. doi: 10.1080/20013078.2019.1684425

61. Bahmer T, Krauss-Etschmann S, Buschmann D, Behrends J, Watz H, Kirsten A-M, et al. RNA-Seq-Based Profiling of Extracellular Vesicles in Plasma Reveals a Potential Role of miR-122-5p in Asthma. Allergy (2020) 76 (1):366-71. doi: 10.1111/all.14486

62. Buschmann D, Kirchner B, Hermann S, Märte M, Wurmser C, Brandes F, et al. Evaluation of Serum Extracellular Vesicle Isolation Methods for Profiling miRNAs by Next-Generation Sequencing. J Extracell Vesicles (2018) 7(1):1481321. doi: 10.1080/20013078.2018.1481321

63. Zhang J, Li S, Li L, Li M, Guo C, Yao J, et al. Exosome and Exosomal microRNA: Trafficking, Sorting, and Function. Genomics Proteomics Bioinf (2015) 13(1):17-24. doi: 10.1016/j.gpb.2015.02.001

64. Kosaka N, Iguchi H, Hagiwara K, Yoshioka Y, Takeshita F, Ochiya T. Neutral Sphingomyelinase 2 (nSMase2)-dependent Exosomal Transfer of Angiogenic microRNAs Regulate Cancer Cell Metastasis. J Biol Chem (2013) 288(15):10849-59. doi: 10.1074/jbc.M112.446831

65. Groot M, Lee H. Sorting Mechanisms for MicroRNAs Into Extracellular Vesicles and Their Associated Diseases. Cells (2020) 9(4):1044. doi: 10.3390/ cells 9041044

66. Koppers-Lalic D, Hackenberg M, Bijnsdorp IV, van Eijndhoven MAJ, Sadek $\mathrm{P}$, Sie D, et al. Nontemplated Nucleotide Additions Distinguish the Small RNA Composition in Cells From Exosomes. Cell Rep (2014) 8(6):1649-58. doi: 10.1016/j.celrep.2014.08.027

67. Guduric-Fuchs J, O’Connor A, Camp B, O’Neill CL, Medina RJ, Simpson DA. Selective Extracellular Vesicle-Mediated Export of an Overlapping Set of microRNAs From Multiple Cell Types. BMC Genomics (2012) 13:357. doi: 10.1186/1471-2164-13-357

68. Wong N, Wang X. miRDB: An Online Resource for microRNA Target Prediction and Functional Annotations. Nucleic Acids Res (2015) 43 (Database issue):D146-52. doi: 10.1093/nar/gku1104

69. Liu T, Zhang Q, Zhang J, Li C, Miao Y-R, Lei Q, et al. EvmiRNA: A Database of miRNA Profiling in Extracellular Vesicles. Nucleic Acids Res (2019) 47 (D1):D89-93. doi: 10.1093/nar/gky985

70. Wen C, Seeger RC, Fabbri M, Wang L, Wayne AS, Jong AY. Biological Roles and Potential Applications of Immune Cell-Derived Extracellular Vesicles. J Extracell Vesicles (2017) 6(1):1400370. doi: 10.1080/20013078.2017.1400370

71. Zhou X, Xie F, Wang L, Zhang L, Zhang S, Fang M, et al. The Function and Clinical Application of Extracellular Vesicles in Innate Immune Regulation. Cell Mol Immunol (2020) 17(4):323-34. doi: 10.1038/s41423-020-0391-1

72. Veerman RE, Güçlüler Akpinar G, Eldh M, Gabrielsson S. Immune CellDerived Extracellular Vesicles - Functions and Therapeutic Applications. Trends Mol Med (2019) 25(5):382-94. doi: 10.1016/j.molmed.2019.02.003

73. Bhatnagar S, Shinagawa K, Castellino FJ, Schorey JS. Exosomes Released From Macrophages Infected With Intracellular Pathogens Stimulate a Proinflammatory Response In Vitro and In Vivo. Blood (2007) 110 (9):3234-44. doi: 10.1182/blood-2007-03-079152

74. Cronemberger-Andrade A, Aragão-França L, de Araujo CF, Rocha VJ, Borges-Silva M da C, Figueira CP, et al. Extracellular Vesicles From Leishmania-infected Macrophages Confer an Anti-Infection CytokineProduction Profile to Naïve Macrophages. PloS Negl Trop Dis (2014) 8(9): e3161. doi: 10.1371/journal.pntd.0003161

75. Tang N, Sun B, Gupta A, Rempel H, Pulliam L. Monocyte Exosomes Induce Adhesion Molecules and Cytokines Via Activation of NF- $\kappa b$ in Endothelial Cells. FASEB J (2016) 30(9):3097-106. doi: 10.1096/fj.201600368RR

76. Dalvi P, Sun B, Tang N, Pulliam L. Immune Activated Monocyte Exosomes Alter microRNAs in Brain Endothelial Cells and Initiate an Inflammatory Response Through the TLR4/MyD88 Pathway. Sci Rep (2017) 7(1):9954. doi: 10.1038/s41598-017-10449-0

77. Kuipers ME, Hokke CH, Smits HH, Nolte-'t Hoen ENM. Pathogen-Derived Extracellular Vesicle-Associated Molecules That Affect the Host Immune
System: An Overview. Front Microbiol (2018) 9:2182. doi: 10.3389/fmicb. 2018.02182

78. Chen Z, Larregina AT, Morelli AE. Impact of Extracellular Vesicles on Innate Immunity. Curr Opin Organ Transplant (2019) 24(6):670-8. doi: 10.1097/MOT.0000000000000701

79. Santos JC, Dick MS, Lagrange B, Degrandi D, Pfeffer K, Yamamoto M, et al. LPS Targets Host Guanylate-Binding Proteins to the Bacterial Outer Membrane for non-Canonical Inflammasome Activation. EMBO J (2018) 37(6):e98089. doi: 10.15252/embj.201798089

80. Codemo M, Muschiol S, Iovino F, Nannapaneni P, Plant L, Wai SN, et al. Immunomodulatory Effects of Pneumococcal Extracellular Vesicles on Cellular and Humoral Host Defenses. MBio (2018) 9(2):e00559-18. doi: 10.1128/mBio.00559-18

81. Lee J, Yoon YJ, Kim JH, Dinh NTH, Go G, Tae S, et al. Outer Membrane Vesicles Derived From Escherichia Coli Regulate Neutrophil Migration by Induction of Endothelial Il-8. Front Microbiol (2018) 9:2268. doi: 10.3389/ fmicb.2018.02268

82. Nandakumar R, Tschismarov R, Meissner F, Prabakaran T, Krissanaprasit A, Farahani E, et al. Intracellular Bacteria Engage a STING-TBK1-MVB12b Pathway to Enable Paracrine cGAS-STING Signalling. Nat Microbiol (2019) 4(4):701-13. doi: 10.1038/s41564-019-0367-z

83. McDonald MK, Tian Y, Qureshi RA, Gormley M, Ertel A, Gao R, et al. Functional Significance of Macrophage-Derived Exosomes in Inflammation and Pain. Pain (2014)155(8):1527-39. doi: 10.1016/j.pain.2014.04.029

84. Giri PK, Schorey JS. Exosomes Derived From M. Bovis BCG Infected Macrophages Activate Antigen-Specific CD4+ and CD8+ T Cells In Vitro and In Vivo. PloS One (2008) 3(6):e2461. doi: 10.1371/journal.pone.0002461

85. Braciale TJ, Morrison LA, Sweetser MT, Sambrook J, Gething MJ, Braciale VL. Antigen Presentation Pathways to Class I and Class II MHC-Restricted T Lymphocytes. Immunol Rev (1987) 98:95-114. doi: 10.1111/j.1600065X.1987.tb00521.x

86. Admyre C, Johansson SM, Paulie S, Gabrielsson S. Direct Exosome Stimulation of Peripheral Human T Cells Detected by ELISPOT. Eur J Immunol (2006) 36(7):1772-81. doi: 10.1002/eji.200535615

87. André F, Chaput N, Schartz NEC, Flament C, Aubert N, Bernard J, et al. Exosomes as Potent Cell-Free Peptide-Based Vaccine. I. Dendritic Cell-Derived Exosomes Transfer Functional MHC Class I/peptide Complexes to Dendritic Cells. J Immunol (2004) 172(4):2126-36. doi: 10.4049/jimmunol.172.4.2126

88. Raposo G, Nijman HW, Stoorvogel W, Liejendekker R, Harding CV, Melief CJ, et al. B Lymphocytes Secrete Antigen-Presenting Vesicles. J Exp Med (1996) 183(3):1161-72. doi: 10.1084/jem.183.3.1161

89. Vincent-Schneider H, Stumptner-Cuvelette P, Lankar D, Pain S, Raposo G, Benaroch P, et al. Exosomes Bearing HLA-DR1 Molecules Need Dendritic Cells to Efficiently Stimulate Specific T Cells. Int Immunol (2002) 14(7):71322. doi: 10.1093/intimm/dxf048

90. Zitvogel L, Regnault A, Lozier A, Wolfers J, Flament C, Tenza D, et al. Eradication of Established Murine Tumors Using a Novel Cell-Free Vaccine: Dendritic Cell-Derived Exosomes. Nat Med (1998) 4(5):594-600. doi: 10.1038/nm0598-594

91. Théry C, Duban L, Segura E, Véron P, Lantz O, Amigorena S. Indirect Activation of Naïve CD4+ T Cells by Dendritic Cell-Derived Exosomes. Nat Immunol (2002) 3(12):1156-62. doi: 10.1038/ni854

92. Montecalvo A, Shufesky WJ, Stolz DB, Sullivan MG, Wang Z, Divito SJ, et al. Exosomes as a Short-Range Mechanism to Spread Alloantigen Between Dendritic Cells During T Cell Allorecognition. J Immunol (2008) 180 (5):3081-90. doi: 10.4049/jimmunol.180.5.3081

93. Tian J, Casella G, Zhang Y, Rostami A, Li X. Potential Roles of Extracellular Vesicles in the Pathophysiology, Diagnosis, and Treatment of Autoimmune Diseases. Int J Biol Sci (2020) 16(4):620-32. doi: 10.7150/ijbs.39629

94. Leone DA, Rees AJ, Kain R. Dendritic Cells and Routing Cargo Into Exosomes. Immunol Cell Biol (2018). doi: 10.1111/imcb.12170

95. Benichou G, Wang M, Ahrens K, Madsen JC. Extracellular Vesicles in Allograft Rejection and Tolerance. Cell Immunol (2020) 349:104063. doi: 10.1016/j.cellimm.2020.104063

96. Muntasell A, Berger AC, Roche PA. T Cell-Induced Secretion of MHC Class II-peptide Complexes on B Cell Exosomes. EMBO J (2007) 26(19):4263-72. doi: $10.1038 /$ sj.emboj. 7601842 
97. Gerondakis S, Siebenlist U. Roles of the NF-kappaB Pathway in Lymphocyte Development and Function. Cold Spring Harb Perspect Biol (2010) 2(5): a000182. doi: $10.1101 /$ cshperspect.a000182

98. Rialland P, Lankar D, Raposo G, Bonnerot C, Hubert P. BCR-Bound Antigen is Targeted to Exosomes in Human Follicular Lymphoma B-Cells. Biol Cell (2006) 98(8):491-501. doi: 10.1042/BC20060027

99. Denzer K, van Eijk M, Kleijmeer MJ, Jakobson E, de Groot C, Geuze HJ. Follicular Dendritic Cells Carry MHC Class II-expressing Microvesicles At Their Surface. J Immunol (2000) 165(3):1259-65. doi: 10.4049/ jimmunol.165.3.1259

100. Blanchard N, Lankar D, Faure F, Regnault A, Dumont C, Raposo G, et al. TCR Activation of Human T Cells Induces the Production of Exosomes Bearing the TCR/CD3/zeta Complex. J Immunol (2002) 168(7):3235-41. doi: 10.4049/jimmunol.168.7.3235

101. Torralba D, Baixauli F, Villarroya-Beltri C, Fernández-Delgado I, LatorrePellicer A, Acín-Pérez R, et al. Priming of Dendritic Cells by DNAcontaining Extracellular Vesicles From Activated T Cells Through Antigen-Driven Contacts. Nat Commun (2018) 9(1):2658. doi: 10.1038/ s41467-018-05077-9

102. Wahlund CJE, Güclüler G, Hiltbrunner S, Veerman RE, Näslund TI, Gabrielsson S. Exosomes From Antigen-Pulsed Dendritic Cells Induce Stronger Antigen-Specific Immune Responses Than Microvesicles In Vivo. Sci Rep (2017) 7(1):17095. doi: 10.1038/s41598-017-16609-6

103. Caruso S, Poon IKH. Apoptotic Cell-Derived Extracellular Vesicles: More Than Just Debris. Front Immunol (2018) 9:1486. doi: 10.3389/fimmu. 2018.01486

104. Park SJ, Kim JM, Kim J, Hur J, Park S, Kim K, et al. Molecular Mechanisms of Biogenesis of Apoptotic Exosome-Like Vesicles and Their Roles as Damage-Associated Molecular Patterns. Proc Natl Acad Sci USA (2018) 115(50):E11721-30. doi: 10.1073/pnas.1811432115

105. Gregory CD, Dransfield I. Apoptotic Tumor Cell-Derived Extracellular Vesicles as Important Regulators of the Onco-Regenerative Niche. Front Immunol (2018) 9:1111. doi: 10.3389/fimmu.2018.01111

106. Dieudé M, Bell C, Turgeon J, Beillevaire D, Pomerleau L, Yang B, et al. The 20S Proteasome Core, Active Within Apoptotic Exosome-Like Vesicles, Induces Autoantibody Production and Accelerates Rejection. Sci Transl Med (2015) 7(318):318ra200. doi: 10.1126/scitranslmed.aac9816

107. Robbins PD, Morelli AE. Regulation of Immune Responses by Extracellular Vesicles. Nat Rev Immunol (2014) 14(3):195-208. doi: 10.1038/nri3622

108. Turpin D, Truchetet M-E, Faustin B, Augusto J-F, Contin-Bordes C, Brisson A, et al. Role of Extracellular Vesicles in Autoimmune Diseases. Autoimmun Rev (2016) 15(2):174-83. doi: 10.1016/j.autrev.2015.11.004

109. Robbins PD, Dorronsoro A, Booker CN. Regulation of Chronic Inflammatory and Immune Processes by Extracellular Vesicles. J Clin Invest (2016) 126(4):1173-80. doi: 10.1172/JCI81131

110. Buzas EI, György B, Nagy G, Falus A, Gay S. Emerging Role of Extracellular Vesicles in Inflammatory Diseases. Nat Rev Rheumatol (2014)10(6):356-64. doi: 10.1038/nrrheum.2014.19

111. Clayton A, Court J, Navabi H, Adams M, Mason MD, Hobot JA, et al. Analysis of Antigen Presenting Cell Derived Exosomes, Based on ImmunoMagnetic Isolation and Flow Cytometry. J Immunol Methods (2001) 247(12):163-74. doi: 10.1016/S0022-1759(00)00321-5

112. Morelli AE, Larregina AT, Shufesky WJ, Sullivan MLG, Stolz DB, Papworth GD, et al. Endocytosis, Intracellular Sorting, and Processing of Exosomes by Dendritic Cells. Blood (2004) 104(10):3257-66. doi: 10.1182/blood-2004-030824

113. Maione F, Cappellano G, Bellan M, Raineri D, Chiocchetti A. Chicken-or-Egg Question: Which Came First, Extracellular Vesicles or Autoimmune Diseases? J Leukoc Biol (2020) 108(2):601-16. doi: 10.1002/JLB.3MR0120-232R

114. Meldolesi J. Extracellular Vesicles, News About Their Role in Immune Cells: Physiology, Pathology and Diseases. Clin Exp Immunol (2019) 196(3):31827. doi: $10.1111 /$ cei. 13274

115. Anel A, Gallego-Lleyda A, de Miguel D, Naval J, Martínez-Lostao L. Role of Exosomes in the Regulation of T-cell Mediated Immune Responses and in Autoimmune Disease. Cells (2019) 8(2):154. doi: 10.3390/cells8020154

116. Minagar A, Jy W, Jimenez JJ, Sheremata WA, Mauro LM, Mao WW, et al. Elevated Plasma Endothelial Microparticles in Multiple Sclerosis. Neurology (2001)56(10):1319-24. doi: 10.1212/WNL.56.10.1319
117. Sáenz-Cuesta M, Osorio-Querejeta I, Otaegui D. Extracellular Vesicles in Multiple Sclerosis: What are They Telling Us? Front Cell Neurosci (2014) 8:100. doi: $10.3389 /$ fncel.2014.00100

118. Potolicchio I, Carven GJ, Xu X, Stipp C, Riese RJ, Stern LJ, et al. Proteomic Analysis of Microglia-Derived Exosomes: Metabolic Role of the Aminopeptidase CD13 in Neuropeptide Catabolism. J Immunol (2005) 175(4):2237-43. doi: 10.4049/jimmunol.175.4.2237

119. de Candia P, De Rosa V, Gigantino V, Botti G, Ceriello A, Matarese G. Immunometabolism of Human Autoimmune Diseases: From Metabolites to Extracellular Vesicles. FEBS Lett (2017) 591(19):3119-34. doi: 10.1002/18733468.12733

120. Zhang H-G, Liu C, Su K, Yu S, Zhang L, Zhang S, et al. A Membrane Form of TNF-alpha Presented by Exosomes Delays T Cell Activation-Induced Cell Death. J Immunol (2006) 176(12):7385-93. doi: 10.4049/jimmunol. 176.12.7385

121. Distler JHW, Jüngel A, Huber LC, Seemayer CA, Reich CF, Gay RE, et al. The Induction of Matrix Metalloproteinase and Cytokine Expression in Synovial Fibroblasts Stimulated With Immune Cell Microparticles. Proc Natl Acad Sci USA (2005) 102(8):2892-7. doi: 10.1073/pnas.0409781102

122. Lo Cicero A, Majkowska I, Nagase H, Di Liegro I, Troeberg L. Microvesicles Shed by Oligodendroglioma Cells and Rheumatoid Synovial Fibroblasts Contain Aggrecanase Activity. Matrix Biol (2012) 31(4):229-33. doi: 10.1016/j.matbio.2012.02.005

123. Berckmans RJ, Nieuwland R, Tak PP, Böing AN, Romijn FPHTM, Kraan $\mathrm{MC}$, et al. Cell-Derived Microparticles in Synovial Fluid From Inflamed Arthritic Joints Support Coagulation Exclusively Via a Factor VII-dependent Mechanism. Arthritis Rheumatol (2002) 46(11):2857-66. doi: 10.1002/ art.10587

124. Cloutier N, Tan S, Boudreau LH, Cramb C, Subbaiah R, Lahey L, et al. The Exposure of Autoantigens by Microparticles Underlies the Formation of Potent Inflammatory Components: The Microparticle-Associated Immune Complexes. EMBO Mol Med (2013) 5(2):235-49. doi: 10.1002/ emmm.201201846

125. Boilard E, Nigrovic PA, Larabee K, Watts GFM, Coblyn JS, Weinblatt ME, et al. Platelets Amplify Inflammation in Arthritis Via Collagen-Dependent Microparticle Production. Science (2010) 327(5965):580-3. doi: 10.1126/ science.1181928

126. Boudreau LH, Duchez A-C, Cloutier N, Soulet D, Martin N, Bollinger J, et al. Platelets Release Mitochondria Serving as Substrate for Bactericidal Group IIA-secreted Phospholipase A2 to Promote Inflammation. Blood (2014) 124 (14):2173-83. doi: 10.1182/blood-2014-05-573543

127. Ullal AJ, Reich CF, Clowse M, Criscione-Schreiber LG, Tochacek M, Monestier M, et al. Microparticles as Antigenic Targets of Antibodies to DNA and Nucleosomes in Systemic Lupus Erythematosus. J Autoimmun (2011) 36(3-4):173-80. doi: 10.1016/j.jaut.2011.02.001

128. Lee JY, Park JK, Lee EY, Lee EB, Song YW. Circulating Exosomes From Patients With Systemic Lupus Erythematosus Induce an Proinflammatory Immune Response. Arthritis Res Ther (2016) 18(1):264. doi: 10.1186/s13075016-1159-y

129. Lee JY, Park JK, Lee EY, Lee EB, Song YW. Correction to: Circulating Exosomes From Patients With Systemic Lupus Erythematosus Induce an Proinflammatory Immune Response. Arthritis Res Ther (2020) 22(1):109. doi: 10.1186/s13075-020-02206-y

130. Rautou P-E, Vion A-C, Amabile N, Chironi G, Simon A, Tedgui A, et al. Microparticles, Vascular Function, and Atherothrombosis. Circ Res (2011) 109(5):593-606. doi: 10.1161/CIRCRESAHA.110.233163

131. Reich N, Beyer C, Gelse K, Akhmetshina A, Dees C, Zwerina J, et al. Microparticles Stimulate Angiogenesis by Inducing ELR(+) CXCChemokines in Synovial Fibroblasts. J Cell Mol Med (2011) 15(4):756-62. doi: 10.1111/j.1582-4934.2010.01051.x

132. Sheng H, Hassanali S, Nugent C, Wen L, Hamilton-Williams E, Dias P, et al. Insulinoma-Released Exosomes or Microparticles Are Immunostimulatory and can Activate Autoreactive T Cells Spontaneously Developed in Nonobese Diabetic Mice. J Immunol (2011) 187(4):1591-600. doi: 10.4049/ jimmunol.1100231

133. Hasilo CP, Negi S, Allaeys I, Cloutier N, Rutman AK, Gasparrini M, et al. Presence of Diabetes Autoantigens in Extracellular Vesicles Derived From Human Islets. Sci Rep (2017) 7(1):5000. doi: 10.1038/s41598-017-04977-y 
134. Rutman AK, Negi S, Gasparrini M, Hasilo CP, Tchervenkov J, Paraskevas S. Immune Response to Extracellular Vesicles From Human Islets of Langerhans in Patients With Type 1 Diabetes. Endocrinology (2018)159 (11):3834-47. doi: 10.1210/en.2018-00649

135. Krishnan P, Syed F, Jiyun Kang N, Mirmira RG, Evans-Molina C. Profiling of RNAs From Human Islet-Derived Exosomes in a Model of Type 1 Diabetes. Int J Mol Sci (2019) 20(23):5903. doi: 10.3390/ijms20235903

136. Guay C, Menoud V, Rome S, Regazzi R. Horizontal Transfer of Exosomal microRNAs Transduce Apoptotic Signals Between Pancreatic Beta-Cells. Cell Commun Signal (2015) 13:17. doi: 10.1186/s12964-015-0097-7

137. Salama A, Fichou N, Allard M, Dubreil L, De Beaurepaire L, Viel A, et al. MicroRNA-29b Modulates Innate and Antigen-Specific Immune Responses in Mouse Models of Autoimmunity. PloS One (2014) 9(9):e106153. doi: 10.1371/journal.pone. 0106153

138. Giri KR, de Beaurepaire L, Jegou D, Lavy M, Mosser M, Dupont A, et al. Molecular and Functional Diversity of Distinct Subpopulations of the Stressed Insulin-Secreting Cell's Vesiculome. Front Immunol (2020) 11:1814. doi: 10.3389/fimmu.2020.01814

139. Figliolini F, Cantaluppi V, De Lena M, Beltramo S, Romagnoli R, Salizzoni $\mathrm{M}$, et al. Isolation, Characterization and Potential Role in Beta CellEndothelium Cross-Talk of Extracellular Vesicles Released From Human Pancreatic Islets. PloS One (2014) 9(7):e102521. doi: 10.1371/ journal.pone.0102521

140. Kim S-J, Chen Z, Essani AB, Elshabrawy HA, Volin MV, Volkov S, et al. Identification of a Novel Toll-Like Receptor 7 Endogenous Ligand in Rheumatoid Arthritis Synovial Fluid That Can Provoke Arthritic Joint Inflammation. Arthritis Rheumatol (2016) 68(5):1099-110. doi: 10.1002/ art.39544

141. Coleman LG, Zou J, Crews FT. Microglial-Derived miRNA Let-7 and HMGB1 Contribute to Ethanol-Induced Neurotoxicity Via TLR7. J Neuroinflam (2017) 14(1):22. doi: 10.1186/s12974-017-0799-4

142. Yelamanchili SV, Lamberty BG, Rennard DA, Morsey BM, Hochfelder CG, Meays BM, et al. MiR-21 in Extracellular Vesicles Leads to Neurotoxicity Via TLR7 Signaling in SIV Neurological Disease. PloS Pathog (2015) 11(7): e1005032. doi: 10.1371/journal.ppat.1005032

143. Ventriglia G, Nigi L, Sebastiani G, Dotta F. Micrornas: Novel Players in the Dialogue Between Pancreatic Islets and Immune System in Autoimmune Diabetes. BioMed Res Int (2015) 2015:749734. doi: 10.1155/2015/749734

144. Olsson R, Carlsson P-O. The Pancreatic Islet Endothelial Cell: Emerging Roles in Islet Function and Disease. Int J Biochem Cell Biol (2006) 38(4):4927. doi: 10.1016/j.biocel.2005.06.021

145. Roggli E, Gattesco S, Caille D, Briet C, Boitard C, Meda P, et al. Changes in microRNA Expression Contribute to Pancreatic $\beta$-Cell Dysfunction in Prediabetic NOD Mice. Diabetes (2012) 61(7):1742-51. doi: 10.2337/db111086

146. Aheget H, Tristán-Manzano M, Mazini L, Cortijo-Gutierrez M, GalindoMoreno P, Herrera C, et al. Exosome: A New Player in Translational Nanomedicine. J Clin Med (2020) 9(8):2380. doi: 10.3390/jcm9082380

147. Malkin EZ, Bratman SV. Bioactive DNA From Extracellular Vesicles and Particles. Cell Death Dis (2020) 11(7):584. doi: 10.1038/s41419-020-02803-4

148. Garcia-Contreras M, Brooks RW, Boccuzzi L, Robbins PD, Ricordi C. Exosomes as Biomarkers and Therapeutic Tools for Type 1 Diabetes Mellitus. Eur Rev Med Pharmacol Sci (2017) 21(12):2940-56.

149. Ventriglia G, Mancarella F, Sebastiani G, Cook DP, Mallone R, Mathieu C, et al. miR-409-3p is Reduced in Plasma and Islet Immune Infiltrates of NOD Diabetic Mice and is Differentially Expressed in People With Type 1 Diabetes. Diabetologia (2020) 63(1):124-36. doi: 10.1007/s00125-01905026-1

150. Sebastiani G, Nigi L, Grieco GE, Mancarella F, Ventriglia G, Dotta F. Circulating microRNAs and Diabetes Mellitus: A Novel Tool for Disease Prediction, Diagnosis, and Staging? J Endocrinol Invest (2017) 40(6):591610. doi: 10.1007/s40618-017-0611-4

151. Dotta F, Ventriglia G, Snowhite IV, Pugliese A. MicroRNAs: Markers of $\beta$ Cell Stress and Autoimmunity. Curr Opin Endocrinol Diabetes Obes (2018) 25(4):237-45. doi: 10.1097/MED.0000000000000420

152. Grieco GE, Cataldo D, Ceccarelli E, Nigi L, Catalano G, Brusco N, et al. Serum Levels of miR-148a and Mir-21-5p Are Increased in Type 1 Diabetic
Patients and Correlated With Markers of Bone Strength and Metabolism. Noncoding RNA (2018) 4(4):37. doi: 10.3390/ncrna4040037

153. Hu Q, Su H, Li J, Lyon C, Tang W, Wan M, et al. Clinical Applications of Exosome Membrane Proteins. Precis Clin Med (2020) 3(1):54-66. doi: 10.1093/pcmedi/pbaa007

154. Tesovnik T, Kovač J, Pohar K, Hudoklin S, Dovč K, Bratina N, et al. Extracellular Vesicles Derived Human-miRNAs Modulate the Immune System in Type 1 Diabetes. Front Cell Dev Biol (2020) 8:202. doi: 10.3389/ fcell.2020.00202

155. Lakhter AJ, Pratt RE, Moore RE, Doucette KK, Maier BF, DiMeglio LA, et al. Beta Cell Extracellular Vesicle miR-21-5p Cargo is Increased in Response to Inflammatory Cytokines and Serves as a Biomarker of Type 1 Diabetes. Diabetologia (2018) 61(5):1124-34. doi: 10.1007/s00125-018-4559-5

156. Mirza AH, Kaur S, Nielsen LB, Størling J, Yarani R, Roursgaard M, et al. Breast Milk-Derived Extracellular Vesicles Enriched in Exosomes From Mothers With Type 1 Diabetes Contain Aberrant Levels of Micrornas. Front Immunol (2019) 10:2543. doi: 10.3389/fimmu.2019.02543

157. Knip M, Virtanen SM, Akerblom HK. Infant Feeding and the Risk of Type 1 Diabetes. Am J Clin Nutr (2010) 91(5):1506S-13S. doi: 10.3945/ ajcn.2010.28701C

158. Lund-Blix NA, Stene LC, Rasmussen T, Torjesen PA, Andersen LF, Rønningen KS. Infant Feeding in Relation to Islet Autoimmunity and Type 1 Diabetes in Genetically Susceptible Children: The MIDIA Study. Diabetes Care (2015) 38(2):257-63. doi: 10.2337/dc14-1130

159. Xu H, Jia S, Xu H. Potential Therapeutic Applications of Exosomes in Different Autoimmune Diseases. Clin Immunol (2019) 205:116-24. doi: 10.1016/j.clim.2019.06.006

160. Jiang Z, Liu Y, Niu X, Yin J, Hu B, Guo S, et al. Exosomes Secreted by Human Urine-Derived Stem Cells Could Prevent Kidney Complications From Type I Diabetes in Rats. Stem Cell Res Ther (2016) 7:24. doi: 10.1186/s13287-016-0287-2

161. Cui C, Ye X, Chopp M, Venkat P, Zacharek A, Yan T, et al. Mir-145 Regulates Diabetes-Bone Marrow Stromal Cell-Induced Neurorestorative Effects in Diabetes Stroke Rats. Stem Cells Transl Med (2016) 5(12):1656-67. doi: $10.5966 /$ sctm.2015-0349

162. Zhang J, Chen C, Hu B, Niu X, Liu X, Zhang G, et al. Exosomes Derived From Human Endothelial Progenitor Cells Accelerate Cutaneous Wound Healing by Promoting Angiogenesis Through Erk1/2 Signaling. Int J Biol Sci (2016) 12(12):1472-87. doi :10.7150/ijbs.15514

163. Li X, Jiang C, Zhao J. Human Endothelial Progenitor Cells-Derived Exosomes Accelerate Cutaneous Wound Healing in Diabetic Rats by Promoting Endothelial Function. J Diabetes Complicat (2016) 30(6):98692. doi: 10.1016/j.jdiacomp.2016.05.009

164. Nakano M, Nagaishi K, Konari N, Saito Y, Chikenji T, Mizue Y, et al. Bone Marrow-Derived Mesenchymal Stem Cells Improve Diabetes-Induced Cognitive Impairment by Exosome Transfer Into Damaged Neurons and Astrocytes. Sci Rep (2016) 6:24805. doi: 10.1038/srep24805

165. Wang X, Gu H, Huang W, Peng J, Li Y, Yang L, et al. Hsp20-Mediated Activation of Exosome Biogenesis in Cardiomyocytes Improves Cardiac Function and Angiogenesis in Diabetic Mice. Diabetes (2016) 65(10):311128. doi: $10.2337 / \mathrm{db} 15-1563$

166. Wang B, Yao K, Huuskes BM, Shen H-H, Zhuang J, Godson C, et al. Mesenchymal Stem Cells Deliver Exogenous MicroRNA-let7c Via Exosomes to Attenuate Renal Fibrosis. Mol Ther (2016) 24(7):1290-301. doi: 10.1038/ mt.2016.90

167. Geiger A, Walker A, Nissen E. Human Fibrocyte-Derived Exosomes Accelerate Wound Healing in Genetically Diabetic Mice. Biochem Biophys Res Commun (2015) 467(2):303-9. doi: 10.1016/j.bbrc.2015.09.166

168. Tsukita S, Yamada T, Takahashi K, Munakata Y, Hosaka S, Takahashi H, et al. MicroRNAs 106b and 222 Improve Hyperglycemia in a Mouse Model of Insulin-Deficient Diabetes Via Pancreatic $\beta$-Cell Proliferation. EBioMedicine (2017) 15:163-72. doi: 10.1016/j.ebiom.2016.12.002

169. Wen D, Peng Y, Liu D, Weizmann Y, Mahato RI. Mesenchymal Stem Cell and Derived Exosome as Small RNA Carrier and Immunomodulator to Improve Islet Transplantation. J Control Release (2016) 238:166-75. doi: 10.1016/j.jconrel.2016.07.044

170. Cantaluppi V, Biancone L, Figliolini F, Beltramo S, Medica D, Deregibus MC, et al. Microvesicles Derived From Endothelial Progenitor Cells Enhance 
Neoangiogenesis of Human Pancreatic Islets. Cell Transplant. (2012) 21 (6):1305-20. doi: 10.3727/096368911X627534.

171. Nojehdehi S, Soudi S, Hesampour A, Rasouli S, Soleimani M, Hashemi SM. Immunomodulatory Effects of Mesenchymal Stem Cell-Derived Exosomes on Experimental Type-1 Autoimmune Diabetes. J Cell Biochem (2018) 119 (11):9433-43. doi: $10.1002 / j c b .27260$

172. Gomzikova MO, James V, Rizvanov AA. Therapeutic Application of Mesenchymal Stem Cells Derived Extracellular Vesicles for Immunomodulation. Front Immunol (2019) 10:2663. doi: 10.3389/ fimmu.2019.02663

173. Gowen A, Shahjin F, Chand S, Odegaard KE, Yelamanchili SV. Mesenchymal Stem Cell-Derived Extracellular Vesicles: Challenges in Clinical Applications. Front Cell Dev Biol (2020) 8:149. doi: 10.3389/ fcell.2020.00149

174. Bulut Ö, GÜrsel İ. Mesenchymal Stem Cell Derived Extracellular Vesicles: Promising Immunomodulators Against Autoimmune, Autoinflammatory Disorders and SARS-CoV-2 Infection. Turk J Biol (2020) 44(3):273-82. doi: 10.3906/biy-2002-79

175. Fierabracci A, Del Fattore A, Luciano R, Muraca M, Teti A, Muraca M. Recent Advances in Mesenchymal Stem Cell Immunomodulation: The Role of Microvesicles. Cell Transplant (2015) 24(2):133-49. doi: 10.3727/ 096368913X675728

176. Tsiapalis D, O’Driscoll L. Mesenchymal Stem Cell Derived Extracellular Vesicles for Tissue Engineering and Regenerative Medicine Applications. Cells (2020) 9(4):991. doi: 10.3390/cells9040991

177. Ramasubramanian L, Kumar P, Wang A. Engineering Extracellular Vesicles as Nanotherapeutics for Regenerative Medicine. Biomolecules (2019) 10 (1):48. doi: 10.3390/biom10010048

178. Baharlooi H, Azimi M, Salehi Z, Izad M. Mesenchymal Stem Cell-Derived Exosomes: A Promising Therapeutic Ace Card to Address Autoimmune Diseases. Int J Stem Cells (2020) 13(1):13-23. doi: 10.15283/ijsc19108

179. Reis M, Mavin E, Nicholson L, Green K, Dickinson AM, Wang X-N. Mesenchymal Stromal Cell-Derived Extracellular Vesicles Attenuate Dendritic Cell Maturation and Function. Front Immunol (2018) 9:2538. doi: 10.3389/fimmu.2018.02538

180. Willis GR, Fernandez-Gonzalez A, Anastas J, Vitali SH, Liu X, Ericsson M, et al. Mesenchymal Stromal Cell Exosomes Ameliorate Experimental Bronchopulmonary Dysplasia and Restore Lung Function Through Macrophage Immunomodulation. Am J Respir Crit Care Med (2018) 197 (1):104-16. doi: 10.1164/rccm.201705-0925OC

181. Ti D, Hao H, Tong C, Liu J, Dong L, Zheng J, et al. LPS-Preconditioned Mesenchymal Stromal Cells Modify Macrophage Polarization for Resolution of Chronic Inflammation Via Exosome-Shuttled Let-7b. J Transl Med (2015) 13:308. doi: 10.1186/s12967-015-0642-6

182. Mokarizadeh A, Delirezh N, Morshedi A, Mosayebi G, Farshid A-A, Mardani K. Microvesicles Derived From Mesenchymal Stem Cells: Potent Organelles for Induction of Tolerogenic Signaling. Immunol Lett (2012) 147 (1-2):47-54. doi: 10.1016/j.imlet.2012.06.001

183. Rahman MJ, Regn D, Bashratyan R, Dai YD. Exosomes Released by IsletDerived Mesenchymal Stem Cells Trigger Autoimmune Responses in NOD Mice. Diabetes (2014) 63(3):1008-20. doi: 10.2337/db13-0859

184. Eirin A, Zhu X-Y, Puranik AS, Tang H, McGurren KA, van Wijnen AJ, et al. Mesenchymal Stem Cell-Derived Extracellular Vesicles Attenuate Kidney
Inflammation. Kidney Int (2017) 92(1):114-24. doi: 10.1016/j.kint. 2016.12.023

185. Kimura K, Hohjoh H, Fukuoka M, Sato W, Oki S, Tomi C, et al. Circulating Exosomes Suppress the Induction of Regulatory $\mathrm{T}$ Cells Via let-7i in Multiple Sclerosis. Nat Commun (2018) 9(1):17. doi: 10.1038/s41467-01702406-2

186. Pieragostino D, Cicalini I, Lanuti P, Ercolino E, di Ioia M, Zucchelli M, et al. Enhanced Release of Acid Sphingomyelinase-Enriched Exosomes Generates a Lipidomics Signature in CSF of Multiple Sclerosis Patients. Sci Rep (2018) 8 (1):3071. doi: 10.1038/s41598-018-21497-5

187. Ohno S-I, Takanashi M, Sudo K, Ueda S, Ishikawa A, Matsuyama N, et al. Systemically Injected Exosomes Targeted to EGFR Deliver Antitumor Microrna to Breast Cancer Cells. Mol Ther (2013) 21(1):185-91. doi: $10.1038 / \mathrm{mt} .2012 .180$

188. Yu S, Liu C, Su K, Wang J, Liu Y, Zhang L, et al. Tumor Exosomes Inhibit Differentiation of Bone Marrow Dendritic Cells. J Immunol (2007) 178 (11):6867-75. doi: 10.4049/jimmunol.178.11.6867

189. Sato YT, Umezaki K, Sawada S, Mukai S, Sasaki Y, Harada N, et al. Engineering Hybrid Exosomes by Membrane Fusion With Liposomes. Sci Rep (2016) 6:21933. doi: 10.1038/srep21933

190. Vázquez-Ríos AJ, Molina-Crespo Á, Bouzo BL, López-López R, MorenoBueno G, de la Fuente M. Exosome-Mimetic Nanoplatforms for Targeted Cancer Drug Delivery. J Nanobiotechnol (2019) 17(1):85. doi: 10.1186/ s12951-019-0517-8

191. Oskouie MN, Aghili Moghaddam NS, Butler AE, Zamani P, Sahebkar A. Therapeutic Use of Curcumin-Encapsulated and Curcumin-Primed Exosomes. J Cell Physiol (2019) 234(6):8182-91. doi: 10.1002/jcp.27615

192. Haney MJ, Zhao Y, Jin YS, Li SM, Bago JR, Klyachko NL, et al. MacrophageDerived Extracellular Vesicles as Drug Delivery Systems for Triple Negative Breast Cancer (Tnbc) Therapy. J Neuroimmune Pharmacol (2020) 15 (3):487-500. doi: 10.1007/s11481-019-09884-9

193. Sidhom K, Obi PO, Saleem A. A Review of Exosomal Isolation Methods: Is Size Exclusion Chromatography the Best Option?. Int J Mol Sci (2020) 21 (18):6466. doi: 10.3390/ijms21186466

194. Théry C, Witwer KW, Aikawa E, Alcaraz MJ, Anderson JD, Andriantsitohaina R, et al. Minimal Information for Studies of Extracellular Vesicles 2018 (MISEV2018): A Position Statement of the International Society for Extracellular Vesicles and Update of the MISEV2014 Guidelines. J Extracell Vesicles (2018) 7(1):1535750. doi: 10.1080/20013078.2018.1535750.

Conflict of Interest: The authors declare that the research was conducted in the absence of any commercial or financial relationships that could be construed as a potential conflict of interest.

Copyright (c) 2021 Grieco, Fignani, Formichi, Nigi, Licata, Maccora, Brusco, Sebastiani and Dotta. This is an open-access article distributed under the terms of the Creative Commons Attribution License (CC BY). The use, distribution or reproduction in other forums is permitted, provided the original author(s) and the copyright owner(s) are credited and that the original publication in this journal is cited, in accordance with accepted academic practice. No use, distribution or reproduction is permitted which does not comply with these terms. 